Article

\title{
Supply and Demand Forecasting of Water Resource Coupling System in Upstream Yangtze River under Changing Environmental Conditions
}

\author{
Sijing Lou ${ }^{1}$, Li Mo ${ }^{1, *}$, Jianzhong Zhou ${ }^{1}$, Yongqiang Wang ${ }^{2}$ and Wenhao $\mathrm{He}^{3}$ \\ 1 School of Civil and Hydraulic Engineering, Huazhong University of Science and Technology, \\ Wuhan 430074, China; sijing_lou@hust.edu.cn (S.L.); jz.zhou@hust.edu.cn (J.Z.) \\ 2 Institute of Comprehensive Utilization of Water Resources, Changjiang River Scientific Research Institute \\ of Changjiang Water Resource Commission, Wuhan 430074, China; wangyq@mail.crsri.cn \\ 3 Hanjiang Water Resources and Hydropower Group Co. LTD, Wuhan 430074, China; hewh_91@163.com \\ * Correspondence: moli@hust.edu.cn; Tel.: +86-15107199572
}

Citation: Lou, S.; Mo, L.; Zhou, J.; Wang, Y.; He, W. Supply and Demand Forecasting of Water Resource Coupling System in Upstream Yangtze River under Changing Environmental Conditions. Water 2021, 13, 640. https://doi.org/ $10.3390 /$ w13050640

Received: 21 January 2021

Accepted: 23 February 2021

Published: 27 February 2021

Publisher's Note: MDPI stays neutral with regard to jurisdictional claims in published maps and institutional affiliations.

Copyright: (c) 2021 by the authors. Licensee MDPI, Basel, Switzerland. This article is an open access article distributed under the terms and conditions of the Creative Commons Attribution (CC BY) license (https:// creativecommons.org/licenses/by/ $4.0 /)$.

\begin{abstract}
The upstream Yangtze River is located in the southwest of central China, where it flows through several ecosystems and densely populated regions that constitute a unique complex coupled system. To determine how the characteristics of supply and demand in a water-coupled system will vary under the influence of climate change and human activity in this area in the next 85 years, the upper Yangtze basin was considered as the study area and was divided into seven sub-basins according to seven main control sections: Shigu, Panzhihua, Xiluodu, Xiangjiaba, Zhutuo, Cuntan, and Yichang; a method for water supply and demand research considering climate change was proposed. Based on simulated runoff in the study area under changing environmental conditions, this study analyzed the available water supply and constructed a long-term water demand forecasting model using the classified water use index method under macro regulation in the study area from 2016 to 2100. The results show that the total water demand in the upstream Yangtze River appears to first increase and then decrease in 2016-2100 and will reach its peak around 2028. The ecological pressure in the upstream Yangtze River increases gradually from upstream to downstream but will not reach the surface water utilization stress threshold (hereinafter referred to as stress threshold) for the next 85 years. The contradiction between monthly supply and demand is more prominent under ecological restrictions. Under the RCP4.5 scenario, water demand exceeds the stress threshold in each sub-basin across several months (mainly March, April, and May), and the water demand nearly reaches the damage threshold in May as the basin extends below the Zhutuo section.
\end{abstract}

Keywords: water supply and demand analysis; water demand forecasting; Yangtze River

\section{Introduction}

The Yangtze River is the largest river in Asia and the third largest worldwide, with rich resources, tributaries, and lakes. The Yangtze River is generally divided into three portions: extending from its source to the Yichang section, it is referred to as "upstream"; from the Yichang section to the Hukou section is "midstream"; and from the Hukou section to its estuary is referred to as "downstream." The upstream Yangtze River is located in the southwest region of central China, where it flows through several ecosystems and densely populated regions. It serves critical functions such as forming an ecological barrier and water source in the river basin and alleviating local ecological and environmental degradation [1].

The variability of ecological and hydrological processes in the basin has been strongly increased by the intensification of global climate change, increase in water demand, and other human activity in recent years [2]. The complex coupled system in the upstream Yangtze River has made it the focus of international research on the response of the ecological environments to climate change and human activity [3-6]. As anthropogenic 
pressure continues to intensify in the upstream basin of the Yangtze River, the high demand for water for social and economic development has exerted a significant impact on the ecological environment in this basin [7]. In order to explore the water supply and demand pattern and its variation law of the water resource coupling system in the upstream Yangtze River in the long-term future, and to provide a reference for developing long-term management plans/policies of local water resources, the upstream Yangtze River Basin was selected as the study area to forecast the contradiction between water supply and demand under the influence of climate change and human activity. The research results have important theoretical and practical significance for protecting the ecological barrier and maintaining social and economic development in this basin.

The changes in hydrological processes directly affect the development and utilization of water resources. In the 1980s, the hydrological communities worldwide began focusing on the impact of environmental changes on hydrology and water resources. Researchers have established a variety of climate models (general circulation models; GCMs) to simulate climate changes caused by human activity under multiple scenarios. GCMs are dynamic models that can provide reliable historical, contemporary, and future climate data to explore the mechanisms of climate change and the associated response of the water cycle [8]. The World Climate Research Program (WCRP) proposed the Coupled Model Intercomparison Project (CMIP) to promote atmospheric, climate system, and regional system models. The CMIP program, implemented in 1995, has produced a fifth revised model (CMIP5) that includes multiple climate system models and earth system models and defines new climate change scenarios, known as representative concentration pathways (RCPs) [9-11]. CMIP5 data under three different greenhouse gas emission scenarios-(RCP2.6 (low emissions), RCP4.5 (medium stable emissions), and RCP8.5 (high emissions)) - were used to analyze future climate scenarios. Since their first use, climate models have been an important tool for evaluating decadal climate change [12,13]. With the development of information technology, combining climate and hydrological models has comprised an important approach for studying the impact of climate change on runoff variation [14-16]. The global climate model of CanESM2 in CMIP5 and RCP2.6, RCP4.5, and RCP8.5 were considered for this study, and the variable infiltration capacity (VIC) macroscale hydrological model was utilized to simulate runoff sequences under different discharge scenarios in the study area.

There are many methods for forecasting water demand considering socioeconomic development, including trend analysis, classified water quota, and mathematical model calculation methods. The trend analysis method is mainly applied to forecast industrial water demand and often includes the Kuznets curve method [17,18]. The classified water quota method is commonly applied for water resource planning, requiring water quota data and social and economic factor forecasting. The mathematical model method requires statistical data from the past several years to establish a model, determine the factors affecting changes in water consumption, identify the relationship between time and water consumption, and forecast water consumption. Commonly used methods include traditional regression analysis [19-21] and gray forecasting models [22-24]. There are also intelligent mathematical models such as artificial neural network models [25-27]), fuzzy mathematics [28], and system dynamics models [29,30]. The trend analysis method cannot reflect the mechanism of water consumption. The data-driven mathematical model method is limited by the short time series of water consumption data; thus, it is only suitable for short-term water demand forecasting. The water quota, which is set every few years in detail by water management agencies, is actually the maximum water that is allowed to be used by each user. Thus, the quota method will always result in overestimated water demand. The historical data of water use spans only 15 years in the upstream Yangtze River, which is unsuitable for a long-term data-driven water demand forecasting. For long-term forecasting, the impact of water use mechanisms and macro-control in China must be considered. 
Considering the impact of climate change on utilizable water, social and economic development on long-term water demand, and various factors on supply and demand contradictions in terms of different measures, an analytic method for determining available water supply and a long-term water demand forecasting model are proposed. The proposed methods were developed to analyze the supply and demand characteristics of water resource coupling systems in the upstream Yangtze River under changing environments. By comprehensively considering the influence of water use mechanisms and macro regulation on future long-term water demand, the classified water use index method under macro regulation was used to construct a long-term water demand forecasting model. The forecasting period was divided into several parts based on the time nodes of macro regulation to enhance the reliability of the forecasting results. The contradiction between supply and demand was analyzed, and a discussion on countermeasures from the perspectives of water supply capacity and utilizable water constraints is presented. The utilizable water constraint is also referred to as ecological constraint, because of the relation of ecological water (in channel) demand and utilizable water. After introducing the study area and describing the socioeconomic structure in Section 3, an analysis of current water supply-use patterns, available water supply, and long-term water demand is presented in Section 4 to evaluate the contradiction between water supply and demand in the water resource coupling system. Finally, conclusions are presented in Section 5.

\section{Materials and Methods}

\subsection{Analytic Methods for Determining Available Water Supply \\ 2.1.1. Runoff Simulation Method}

Specific climate scenarios of the Coupled Model Intercomparison Project Phase 5 (CMIP5) were introduced to reflect the impact of climate change on runoff. The runoff series of study areas in the next 82 years were simulated using a distributed hydrological model VIC model based on CMIP5 climate projections.

The VIC model divides the watershed into several grids, and each grid has many vegetation types. For each vegetation type, characteristic vegetation parameters were formulated, including LAI (leaf area index), vegetation albedo, vegetation minimum impedance, structural impedance, roughness length, root system distribution of each soil layer, and zero plane displacement of vegetation. Evaporation data were obtained by calculating the net radiation and water vapor pressure difference using the PenmanMonteith equation. In the basin, the soil was divided into three layers. The top two layers were used to simulate the rapid response process of soil to rainfall infiltration, and the bottom layer was used to simulate the seasonal soil moisture process and the short-term rainfall infiltration process when the upper soil was saturated. The water in the underlying soil was absorbed from the middle layer under the action of natural gravity, and the Brooks Corey equation was used to simulate the unsaturated water conduction process [31]. The bottom outflow process can be expressed according to the Arno model [32]. Soil water can also be transmitted from the root system via transpiration. The soil characteristic parameters (such as soil texture and hydraulic conductivity) in each grid are constant. In this model, soil water distribution, infiltration, inter-layer water conversion, surface outflow, and underground outflow of each vegetation type were calculated at each time step. For each grid, the total heat flux (latent, sensible, and geothermal), effective surface temperature, and total surface and subsurface outflow were weighted according to the proportion of each vegetation type.

The steps for applying the VIC model are as follows:

1. Select control sections and determine the basin boundary and river network based on digital elevation model (DEM) data.

2. Resample DEM data into several grids at specific latitudes, and number them from west to east and north to south.

3. Use ArcGIS to generate grid flow, and manually judge and adjust the resulting grid. 
4. Determine the distribution of soil type in the upper and lower layers in the control basin and calculate the proportion of different types of vegetation in each grid.

5. Sort and interpolate the meteorological data sequence to each grid in the basin. Export the meteorological input file of the flow generation module of the VIC model, and determine the flow generation ratio of the boundary grid.

6. Calibrate and test VIC model parameters.

7. Select the global climate model and typical emission path to form an emission scenario. Take the downscaling data of meteorological compression in each emission scenario as the input value and run the calibrated VIC model to simulate the future runoff sequence of the basin.

\subsubsection{Available Water Supply Forecasting Method}

Available surface water supply can be analyzed by using an inverse or positive algorithm. With the inverse algorithm, the available surface water supply was calculated as the annual average water volume in a river minus the water that cannot be used (minimum ecological water demand in the river) and unavailable surface water (annual average volume of abandoned water in the flood season). In contrast to the inverse algorithm, the positive algorithm focuses on how much water can be used by analyzing projects' supply capacity, water demand, and so on.

As the surface water supply in the study area (upstream Yangtze River) accounts for more than $90 \%$ of the total water supply, the available surface water supply was considered, and the terms "available water supply" and "utilizable water" refer only to surface water resources in this study. The available water supply was determined jointly by identifying the amount of utilizable water and supply capacity in the study area.

Utilizable water, which corresponds to the result of the inverse algorithm, refers to the amount of usable water limited to the maximum exploitation amount. At present, most experts in China and abroad agree that the rational maximum development proportion of water resources should not exceed $40 \%$ of the total water resources to maintain the ecological water demand [33-35]. On this basis, the concept of the surface water utilization threshold coefficient has been introduced to represent a reasonable maximum exploitation proportion of the study area, which is expressed by $\beta$. Then, the utilizable water $\left(W_{A}\right)$ can be expressed by the total runoff $\left(W_{R}\right)$. The threshold coefficient $(\beta)$ was calculated as shown in Equation (1):

$$
W_{A}=W_{R} \times \beta
$$

The European Environment Agency indicates that areas with WEI+ above $40 \%$ are considered subject to unsustainable use of freshwater resources, areas with WEI+ values between $20 \%$ and $40 \%$ are water-deficit areas, and areas with WEI+ values below $20 \%$ are non-stress areas [36-38]. Then, corresponding to the two boundaries presented above (non-stress to water-deficit areas, and water-deficit to unsustainable areas), $20 \%$ and $40 \%$ were taken as the stress $\left(\beta_{1}\right)$ and damage $\left(\beta_{2}\right)$ threshold coefficient of surface water utilization, respectively. When the regional water demand exceeds the available water supply, there is a contradiction between water supply and the local ecological environment protection. This contradiction can be alleviated by implementing water reclamation and other source supply projects or by improving water-conserving technology and enhancing water conservation awareness.

Identifying available water supply is also related to evaluating the capacity of water supply projects in the basin. Surface water supply projects are those with surface water sources such as reservoirs, ponds, rivers, and lakes and can be classified into storage, diversion, and pumping projects. Storage projects refer to reservoirs and embankments, excluding non-irrigated fish ponds, waterlogged ponds, and so on. Diversion projects direct water from river channels, lakes, and other surface waters by artesian flow, and pumping projects carry water from surface water sources, such as rivers and lakes. The contradiction between supply and demand caused by water supply projects' capacity can 
be alleviated by engineering approaches such as the construction of water supply facilities and non-engineering measures such as optimal scheduling.

\subsection{Water Demand Forecasting Method}

In the long-term water demand forecast, more attention should be paid to the impact of water use mechanisms and macro regulation on water demand in China. Focusing on this question, the classified index forecasting method under macro regulation is proposed. The influence of the water use mechanism and macro regulation on future water use changes is taken into comprehensive consideration, and the reliability of forecasting results is enhanced by segmenting the forecasting period based on macro regulation. The classified index method under macro regulation, an improvement based on the classified water quota method, was used to forecast water demand. The classified water quota method is a common method for water demand forecasting [39,40], but its results are often overestimated due to high quotas. Macro regulation refers to an adjustment and control method carried out by the government, comprehensively using various means for the national social economy and other aspects, such as resources and the environment. By considering macro regulation efforts, the classified index method can improve the water quota method, and the results become more practical, especially for long-term forecasting.

According to different types of water users, the method classifies water use or demand into four parts - domestic, agricultural, industrial, and environmental parts-and forecasts the water demand of each part through the following main steps, as shown in Figure 1.

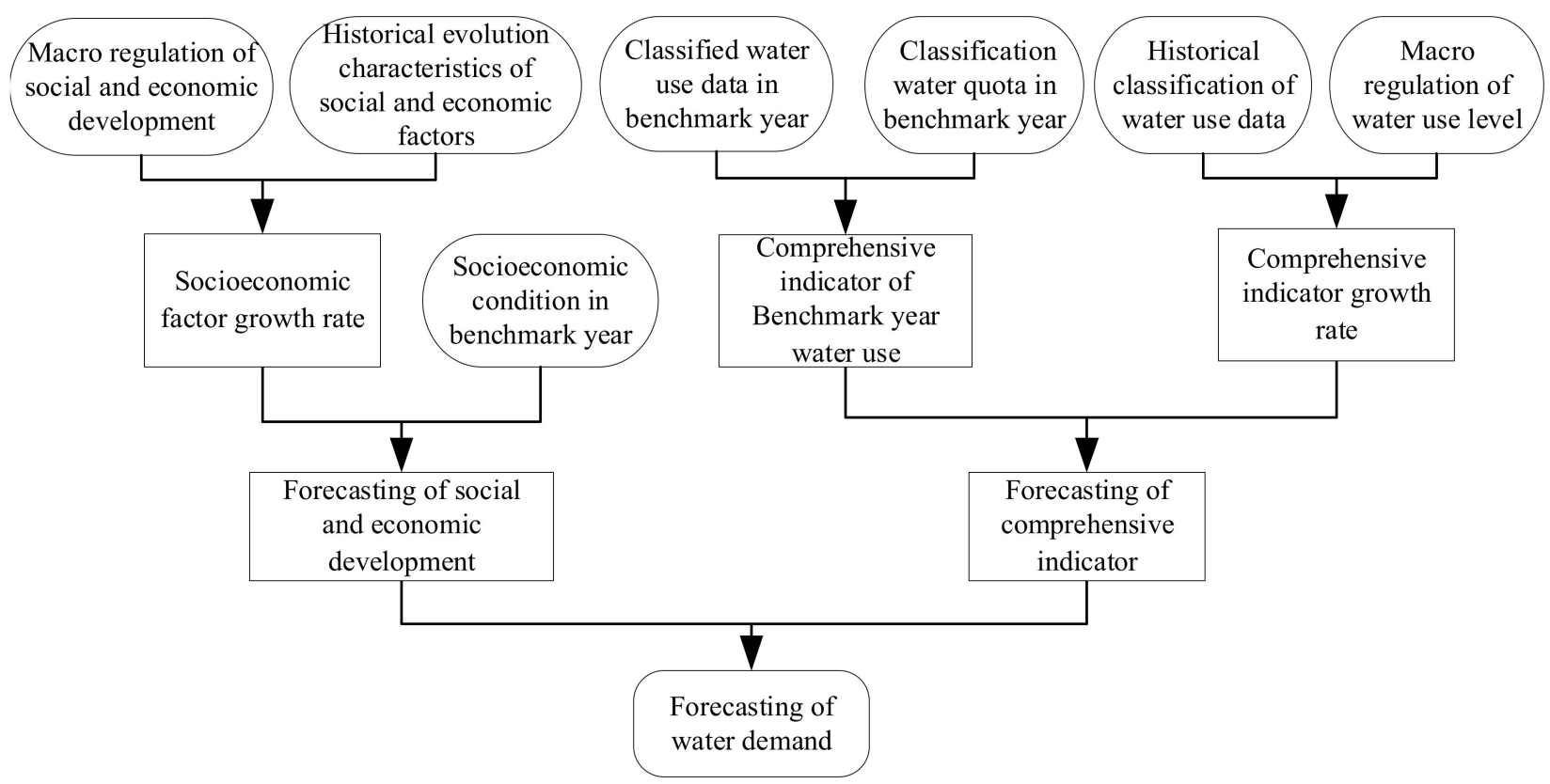

Figure 1. Schematic diagram of water demand forecasting process using classified water index method under macro regulation.

- Analyze social and economic factors variation under macro regulation.

- Analyze water use index variation under macro regulation.

- Forecast water demand based on the results of steps 1 and 2.

According to the various living environments in rural and urban areas, the current water demand forecast mainly involves domestic water for urban residents, urban public, rural residents, and large or small livestock. Domestic water for residents and livestock includes drinking, cleaning, and other uses; urban public water use refers to the amount of water used to maintain urban public facilities and environments. With the development and preliminary results of China's new rural construction and urban-rural integration process, rural public water demand should be considered in the new round of domestic water 
demand forecast. The main socioeconomic factors involved in the forecasting of domestic water demand include urban and rural populations as well as the amount of small and large livestock, while the involved water use indices include water use indices for urban residents, urban public, rural residents, large and small livestock, and rural public life. Domestic water use indices include the water requirement (L) for per urban/rural resident and per large/small livestock per day. Thus, the corresponding socioeconomic indicators are the populations of urban/rural residents and large/small livestock. According to the definition of the index, the relationship between annual water demand $\left(\mathrm{m}^{3}\right)$ and water use indices in urban and rural areas is shown in Equations (2) and (3).

$$
\begin{gathered}
W_{u l, i}=0.365 \times P_{u l, i} \times m_{u l, i} \\
W_{r l, i}=0.365\left(P_{r l, i} \times m_{r l p, i}+Q M_{i} \times m_{q m, i}+Q N_{i} \times m_{q m, i}\right)
\end{gathered}
$$

where $W_{u l, i} W_{r l, i}$ refers to the domestic water demand of urban and rural residents in the ith year; $P_{u l, i}$ and $P_{r l, i}$ refer to the urban and rural population in the ith year; $Q M_{i}$ and $Q N_{i}$ refer to the number of large and small livestock in the ith year; $m_{u l, i}, m_{r l, i}, m_{q m, i}$ and $m_{q n, i}$ refer to the water index for urban comprehensive (urban residents and urban public), rural comprehensive (rural residents and rural public), and large and small livestock in the ith year.

Agricultural water demand mainly comprises farmland, forest, grassland irrigation, and fish pond replenishing water and is characterized by high demand, poor use efficiency, and high pollution because traditional irrigation methods such as flood irrigation are applied in most areas. Considering the low utilization rate of irrigation water, irrigation water carries fertilizer (including $\mathrm{N}$ and $\mathrm{P}$ ) from the field back to the river after irrigation, leading to a water eutrophication risk. Therefore, agricultural water has always been a key part of water conservation work. The main socioeconomic factors involved in forecasting agricultural water demand include cultivated land, farmland irrigation, forest and fruit land irrigation, grassland effective irrigation, and fish pond areas. The indices of water use include a net quota of irrigation, effective utilization coefficient (EUC) of irrigation water, and quota of fish pond replenishment. Agricultural water use indices include net irrigation/replenish quota (water requirements $\left(\mathrm{m}^{3}\right)$ for a unit area (ha) used to grow crops/fruit trees/grasslands, or refill fish ponds), and EUC of irrigation water (ratio of net water requirements to irrigated water supply). The corresponding socioeconomic indicator is the irrigated/replenished area (ha). The relationship between annual agricultural water demand $\left(\mathrm{m}^{3}\right)$ and water use indices is shown in Equations (4) to (7).

$$
\begin{aligned}
W_{L I, i} & =\frac{A_{L I, i} \times m_{L I, i}}{\eta_{i}} \\
W_{F I, i} & =\frac{A_{F I, i} \times m_{F I, i}}{\eta_{i}} \\
W_{G I, i} & =\frac{A_{G I, i} \times m_{G I, i}}{\eta_{i}} \\
W_{F P, i} & =A_{F P, i} \times m_{F P, i}
\end{aligned}
$$

where $W_{L I, i}, W_{F I, i}, W_{G I, i}$, and $W_{F P, i}$ refer to water demand for farmland, forest and fruit land, and grassland irrigation, and fish pond replenish in the ith year, respectively; $A_{L I, i}$, $A_{F I, i}, A_{G I, i}$, and $A_{F P, i}$ refer to their irrigated or replenished area in the ith year, respectively; $m_{L I, i}, m_{F I, i}, m_{G I, i}$ and $m_{F P, i}$ refer to their water use index or quota, respectively; and $\eta_{i}$ refers to the EUC of irrigation.

For industrial water demand, the data are complicated and difficult to obtain owing to the diversity of and distinct statistical standards for industrial types. Therefore, it is impossible to consider industrial water demand from the classification of the water use mechanism in the calculation. However, industrial water use has a high reuse rate, 
and the change in water demand can be reflected by the change in industrial production (1000 yuan), an index of the water requirement $\left(\mathrm{m}^{3}\right)$ for per unit industrial production (1000 yuan), and reuse rate. The relationship between annual industrial water demand and water use indices is shown in Equation (8).

$$
W_{F, i}=G_{i} \times m_{F, i} \times\left(1-c_{i}\right)
$$

where $W_{F, i}$ refers to industrial water demand in the ith year, $G_{i}$ refers to industrial production in the ith year, $m_{F, i}$ refers to industrial water use index in the ith year, and $c_{i}$ refers to the water reuse rate in the ith year.

The environmental water demand is divided into the internal river and external river water demand, among which the external river water demand, which was taken out of the river, mainly includes the water needed to keep the city clean and green. The water demand of this kind was considered the same as the water demand of the public life part and did not require recalculation. Internal river water demand was reserved in the analysis of available water supply and did not require recalculation.

\section{Study Area}

The Yangtze River has important ecological barrier and water supply functions in the river basin and plays a key role in alleviating local ecological environment degradation, forming a complex coupled system. The upstream Yangtze River covers an area of approximately 1 million $\mathrm{km}^{2}$. The major tributaries of the Yangtze River include the Jinsha, Yalong, Mintuo, Jialing, and Wujiang tributaries and span 38 cities across 6 provinces, including Sichuan, Qinghai, Guizhou, Yunnan, Gansu, and Hubei. The upstream Yangtze River is characterized by complex and variable topography as an important part of the Qinghai-Tibet Plateau with karst and other special terrain and more mountainous and hilly areas [41,42]. In the basin, the population presents a regional aggregation feature in the area that is sparse above the Shigu section and gradually increases from the Shigu section to the bottom, with human activity gradually increasing in frequency. The climate of the upstream Yangtze River belongs to the Qinghai-Tibet alpine region and subtropical monsoon region. The water sources in the region are mainly the melting snow and rainfall on the plateau. The flood season in this area generally spans May to October, and the rainfall during the flood season accounts for more than $70 \%$ of total annual rainfall. The precipitation in the basin ranges from 800 to $1200 \mathrm{~mm}$ per year, exhibiting uneven spatial and temporal distribution [43].

To analyze the spatial distribution of the contradiction between supply and demand in the upstream Yangtze River, seven main control sections-Shigu, Panzhihua, Xiluodu, Xiangjiaba, Zhutuo, Cuntan, and Yichang-were selected from the upper reaches to divide the upstream Yangtze River into seven sub-basins, as shown in Figure 2. The seven subbasins are distributed in the Jinsha, Yalong, Mintuo, Jialing, Wujiang, and main streams.

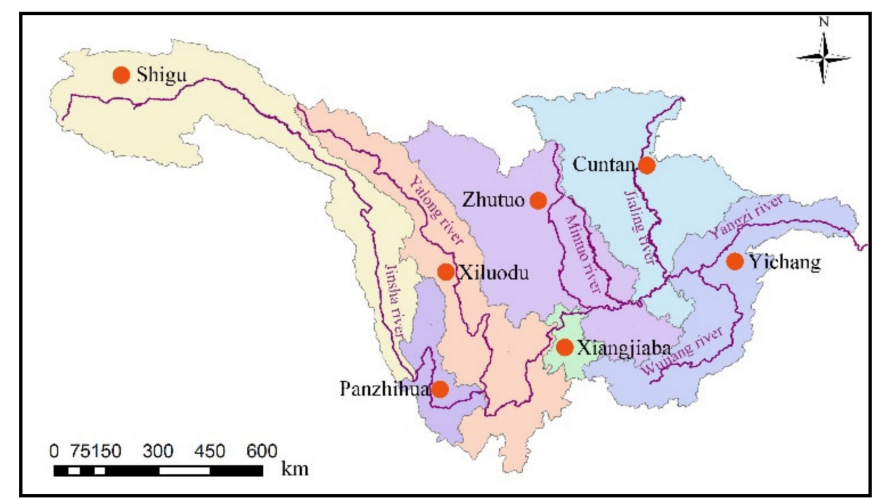

Figure 2. Sub-basins of upstream Yangtze River based on seven main control sections. 
The study area is sparsely populated with low-intensity human activity above the Shigu section, which gradually increases from the Shigu section to the bottom. According to the national, provincial, and city data from China [44] obtained during 2011-2015, the population of this basin continued to rise at a rate of $5 \%$, which is higher than the national average growth rate of $2 \%$, and reached 155 million in 2015 with a lower urbanization rate of $50.0 \%$ (compared with the national rate $56 \%$ in 2015 ).

In 2015, the total upstream gross domestic product (GDP) reached 6.14 trillion yuan, with a per-capita GDP of 39,600 yuan, which was less than the national per-capita average of 49,900 yuan. Upstream regions of Chongqing and Hubei, whose economies are relatively developed, have a per-capita GDP of more than 50,000 yuan. The provinces of Sichuan, Yunnan, Gansu, and Guizhou have a per-capita GDP of approximately 30,000 yuan, with less developed economies and high potential. From 2011 to 2015, GDP maintained a continuous growth trend, but the growth rate slowed down to $6 \%$ in 2015 from $18 \%$ in 2011 in the upstream, which was consistent with the national GDP change trend. According to the "Classification of Three Industries" established by New Zealand economist Fisher, agriculture, including farming, forestry, animal husbandry, and fishery, is classified as the primary industry; manufacturing/construction industry is classified as secondary industry; and circulation/service industry is classified as tertiary industry. From the perspective of industrial structure, the agricultural output (primary industry) in 2015 was 664.6 billion yuan, secondary industry was 2692 billion yuan, and tertiary industry was 2783.2 billion yuan, with an industry structure of 10.8:43.8:45.3 in the upstream. The proportions of primary industrial output in Yunnan, Sichuan, Gansu, Guizhou, and Hubei were 15\%, 12\%, $14 \%, 15 \%$, and $11 \%$ higher than the upstream average, respectively. Qinghai, Chongqing, and Hubei exhibited advantages in secondary industry, while Gansu and Chongqing had advantages in tertiary industry. Compared with the national industry structure in the same year of 8.4:41.11:50.46, as shown in Figure 3, the industries in the upstream exert stress on agriculture and the secondary industry, while the tertiary industry lagged.

Upstream Yangzi river

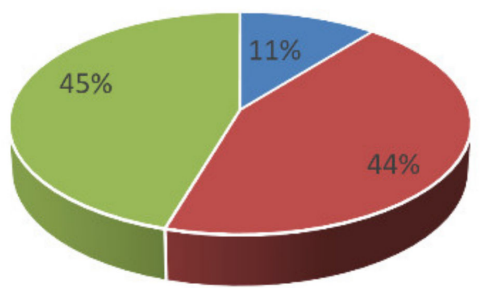

China

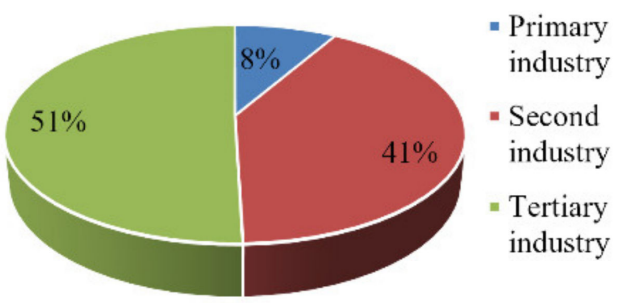

Figure 3. Industry structure in upstream Yangtze River Basin and in China.

In terms of agricultural patterns, a well-known agricultural production base, Sichuan Basin, is located in this area and is among the main grain-producing areas in China. The main crops in this region are food crops, which are supplemented by cash crops; among cash crops, rice, wheat, corn, and sweet potato occupy dominant positions. Rice accounts for $47.1 \%$ of total grain output, wheat accounts for $15.3 \%$, corn accounts for $18.0 \%$, and sweet potatoes account for $10.7 \%$. Cash crops include a wide variety of plants such as cotton, oil, sugar cane, fruit, tea, tobacco, hemp, and medicinal materials. The total area of cultivated land in the basin was 13.49 million ha in 2015, of which only 4.61 million ha was irrigated, with an irrigated ratio of only $34.2 \%$. The proportion of the irrigated area in Sichuan and Hubei was relatively higher, while that in other regions was less than $40 \%$, which is far lower than the national average of $48.8 \%$. 


\section{Results and Discussion}

\subsection{Analysis of Current Water Supply-Use Pattern}

According to the data published by China Water Resources Bulletin [45] and Changjiang and Southwest Rivers Water Resources Bulletin [46], the average annual runoff in the upstream Yangtze River is $428 \mathrm{Bm}^{3}$ (Billion $\mathrm{m}^{3}$ ), and per-capita water resources in the upper reaches of the Yangtze River is only $2700 \mathrm{~m}^{3}$, which is slightly higher than the national average but only $30 \%$ of the world's average. In recent years, the annual runoff of the Yichang section (the outflow boundary of upstream), as well as the total amount of water resources in upstream, shows a downward trend, and the water resource per-capita decreased after a plateau period, as shown in Figures 4 and 5.

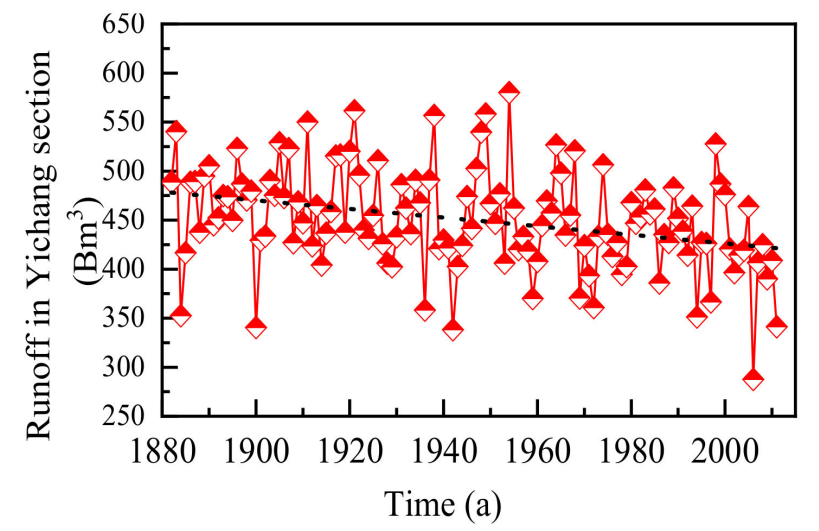

Figure 4. Change in annual runoff in Yichang section.

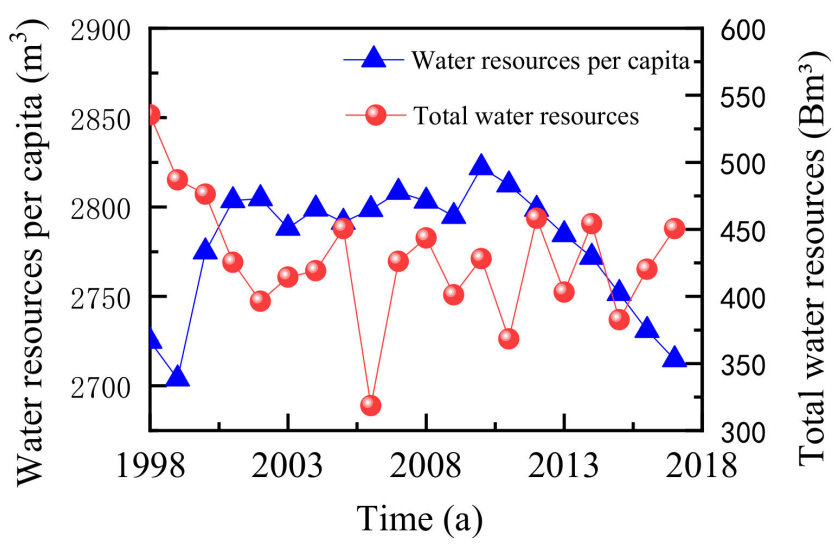

Figure 5. Change in water resource in Yichang section.

Figure 6 shows that the total amount of water use in the upstream continued to rise from 2001 to 2017. Domestic and agricultural water use showed a trend of first plateauing and then decreasing, while industrial water use first increased and then decreased, both exhibiting a change in 2009. Similarly, the water use proportion for the upstream industry gradually decreased, while that for life and agriculture increased since 2009, as shown in Figure 7, which reflects the continuous improvement of living standards and agricultural irrigation facilities upstream. The irrigated farmland area will stop increasing at some point in the future due to limited land area, and both the amount and proportion of agricultural water use will gradually decrease as water-conserving irrigation technology improves. 


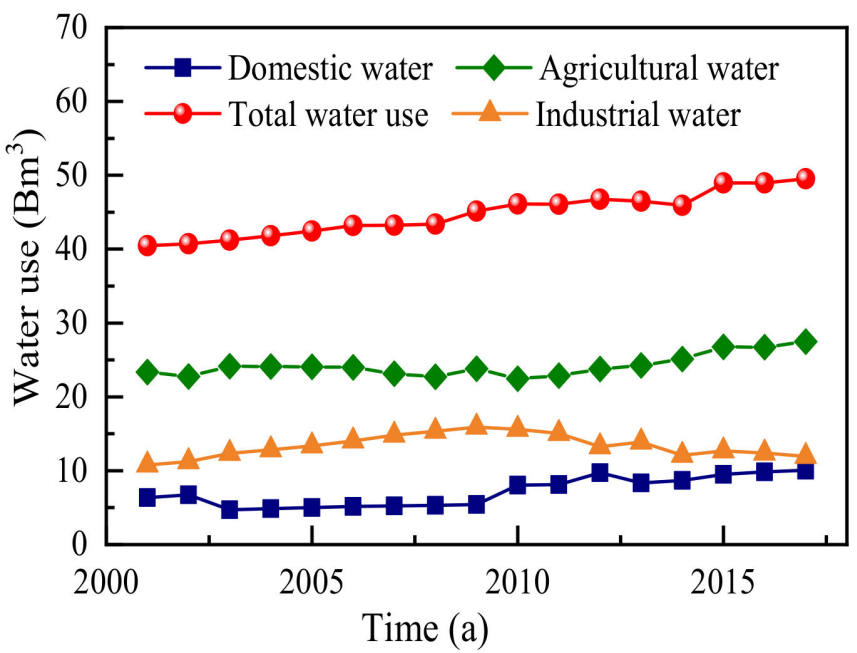

Figure 6. Change in basin water use.

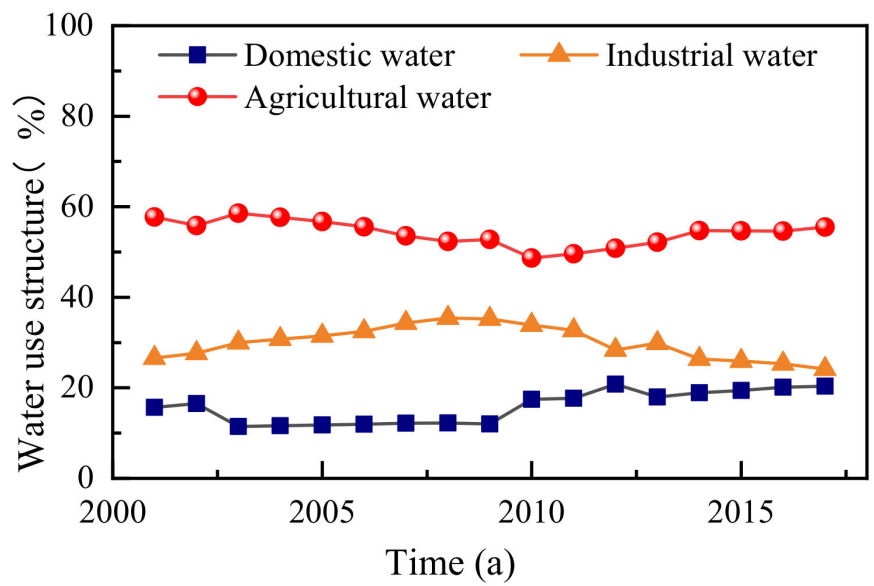

Figure 7. Change in basin water use structure.

Water use efficiency is typically reflected by classified water use indicators, such as domestic water per capita (DWC), industrial water per 1000-yuan industrial production (IWIP-1000), and agricultural irrigation water per ha (AIWH); comprehensive water use indicators such as total water use per-capita (TWC) and total water use per 1000-yuan GDP (TWGP-1000) are also used. As shown in Figure 8, the DWC and IWIP-1000 presented significantly increasing and decreasing trends, respectively, and AIWH decreased slowly, while TWC grew slowly, and TWGP-1000 declined significantly from 1998 to 2017 in the upstream. In the same period, the total amount of water use in the whole Yangtze basin generally tended to remain stable, and the indicators mentioned above changed more slowly than upstream [28]. The indicators upstream turned from worse to better than the whole Yangtze basin during recent years (2000-2017) and contributed significantly to the improvement of water use efficiency in the Yangtze basin.

Controlling and improving water use efficiency is necessary to reduce the total amount of water used and minimize the discharge of wastewater, both of which protect the ecological barrier in the upstream Yangtze River. 


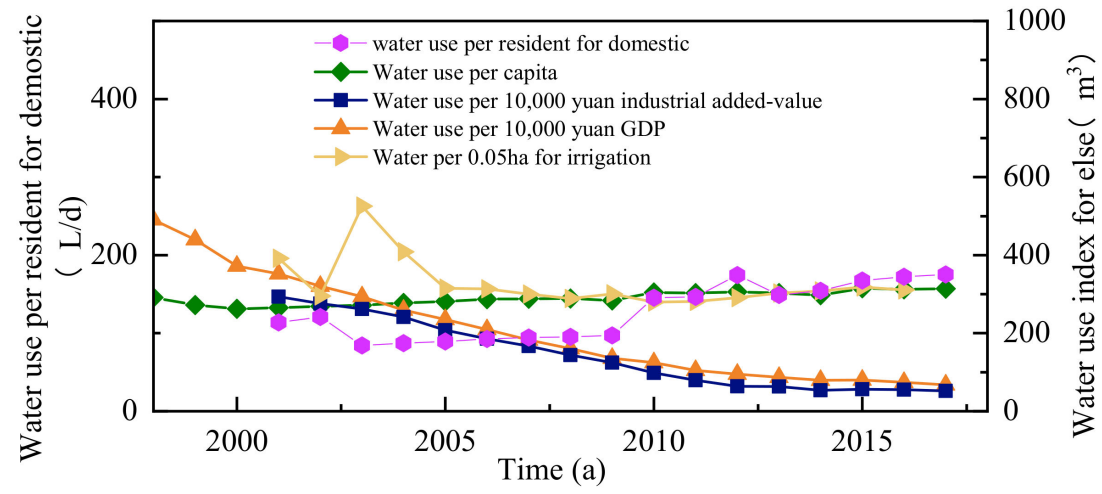

Figure 8. Changes in water use indices in the upstream Yangtze River.

\subsection{Analysis of Water Supply Capacity and Utilizable Water}

The available water supply is influenced by the capacity of water supply projects and the amount of utilizable water resources. The available water supply analysis should first ascertain the local water supply structure, including the proportion and sequence of different sources, and then analyze the water supply capacity and utilizable water resources according to the water supply mechanism of each source.

\subsubsection{Runoff Simulation of Sub-Basin in Upstream Yangtze River}

The CanESM2 global climate model has a strong ability to simulate meteorological factors such as temperature and precipitation in China [47]. Considering the impact of climate change on the hydrological process in the study area, the CanESM2 global climate model and typical concentration path RCP2.6, RCP4.5, and RCP8.5 were selected, and the VIC model was used to simulate the upstream runoff process in the future under climate change. The modeling process is briefly described below.

First, the DEM data of the study area were imported into ArcGIS, and the study area was divided into seven sub-basins according to control sections and in grids with a horizontal resolution of $0.5^{\circ} \times 0.5^{\circ}$. Then, the flow direction and the distribution of soil and vegetation were determined, and the meteorological data were interpolated into each grid. Second, the parameters of the VIC model were calibrated using meteorological and runoff data from 1 July 2014, to 30 June 2017, and verified using data from 1 July 2017 to 30 June 2018. The optimal parameters and Nash-Sutcliffe efficiency (NSE) coefficient are shown in Table 1. Finally, the daily meteorological data from 2016 to 2100 under the typical discharge path were extracted and scaled down as input to drive the VIC model and obtain the daily runoff under each section from 2016 to 2100 . The annual runoff was sorted as shown in Figure 9. The runoff of each section corresponds to the runoff from the source to the section upstream of the Yangtze River.

Table 1. Parameters, NSE, and total error (ER) of VIC model in calibration and validation.

\begin{tabular}{|c|c|c|c|c|c|c|c|c|c|c|c|}
\hline \multirow{2}{*}{ Section } & \multicolumn{7}{|c|}{ Parameters } & \multicolumn{2}{|c|}{ Calibration } & \multicolumn{2}{|c|}{ Validation } \\
\hline & B & Ds & Dm & Ws & d1 & d2 & d3 & NSE & ER & NSE & ER \\
\hline Shigu & 0.39 & 0.27 & 12.51 & 0.31 & 0.035 & 0.274 & 0.51 & 0.835 & 0.145 & 0.843 & 0.060 \\
\hline Panzhihua & 0.48 & 0.11 & 15.25 & 0.31 & 0.047 & 0.215 & 1.18 & 0.822 & 0.040 & 0.850 & 0.028 \\
\hline Xiluodu & 0.49 & 0.84 & 12.11 & 0.99 & 0.044 & 0.284 & 2.41 & 0.861 & 0.035 & 0.878 & 0.041 \\
\hline Xiangjiaba & 0.47 & 0.75 & 112.61 & 0.89 & 0.076 & 0.302 & 2.42 & 0.859 & 0.012 & 0.874 & 0.055 \\
\hline Zhutuo & 0.62 & 0.88 & 15.05 & 0.89 & 0.013 & 0.304 & 3.21 & 0.885 & 0.021 & 0.875 & 0.060 \\
\hline Cuntan & 0.62 & 0.80 & 13.23 & 0.95 & 0.054 & 0.284 & 2.73 & 0.891 & 0.025 & 0.885 & 0.055 \\
\hline Yichang & 0.55 & 0.33 & 13.22 & 0.98 & 0.079 & 0.305 & 3.01 & 0.722 & 0.004 & 0.765 & 0.039 \\
\hline
\end{tabular}



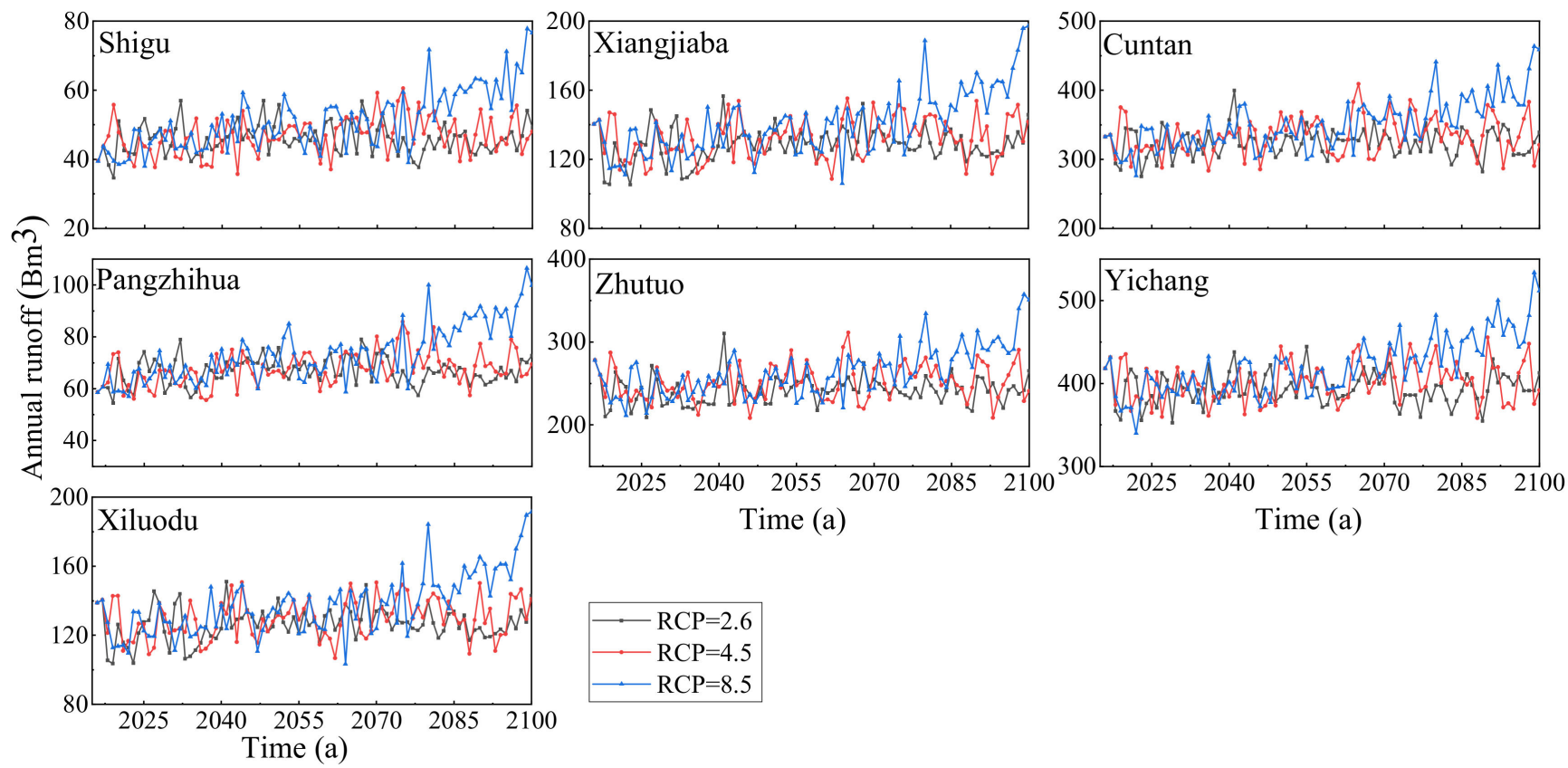

Figure 9. Predicted annual runoff under different emission scenarios for each section of the study area.

\subsubsection{Forecasting of Utilizable Surface Water Resources in the Upstream Basin}

Combined with the runoff simulation results of the VIC model under climate change conditions, the utilizable threshold of surface water of each sub-basin was calculated according to Formula (1). RCP4.5 emissions were taken as an example, as shown in Figure 10.
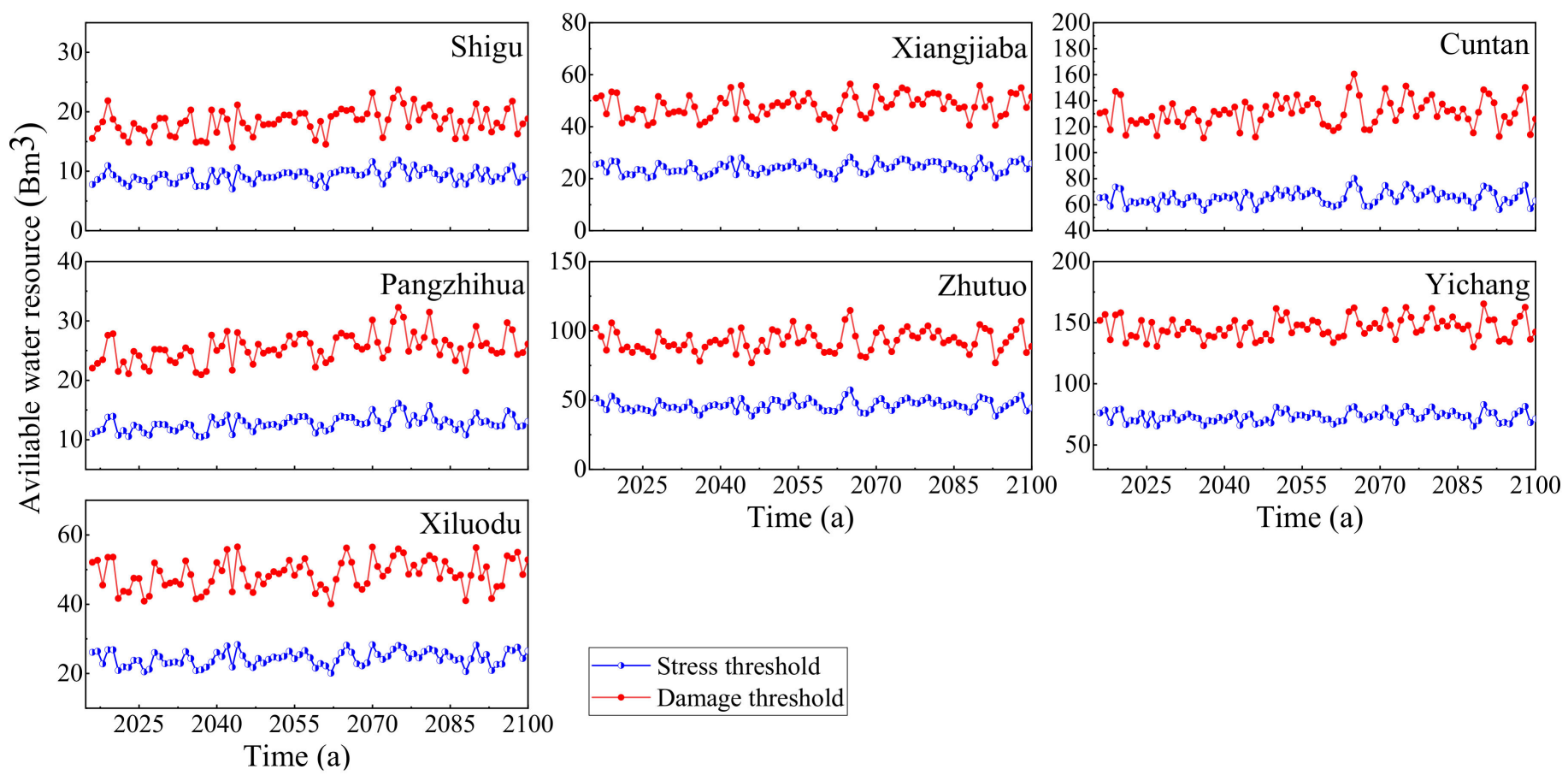

Figure 10. Utilizable threshold of surface water resources in evaluated sections of the upstream basin. 


\subsubsection{Analysis of Water Supply Structure in Upstream Yangtze River}

The main water source for the upstream Yangtze River basin is surface water. The water resources and supply structure of the upstream Yangtze River Basin from 2000 to 2017 are shown in Figures 11 and 12. All data were taken from the Changjiang and Southwest Rivers Water Resources Bulletin [45].

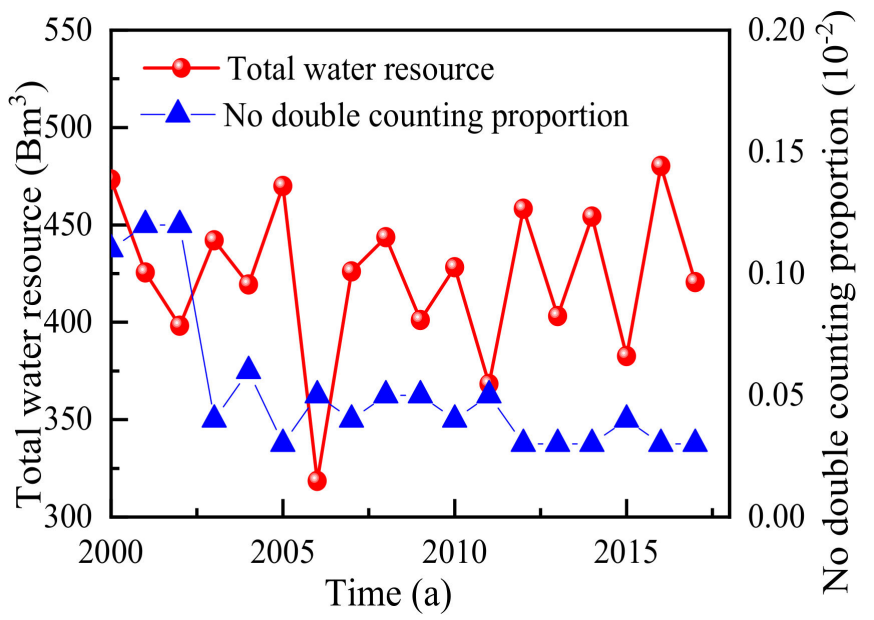

Figure 11. Historical water resource structure in upstream Yangtze River.

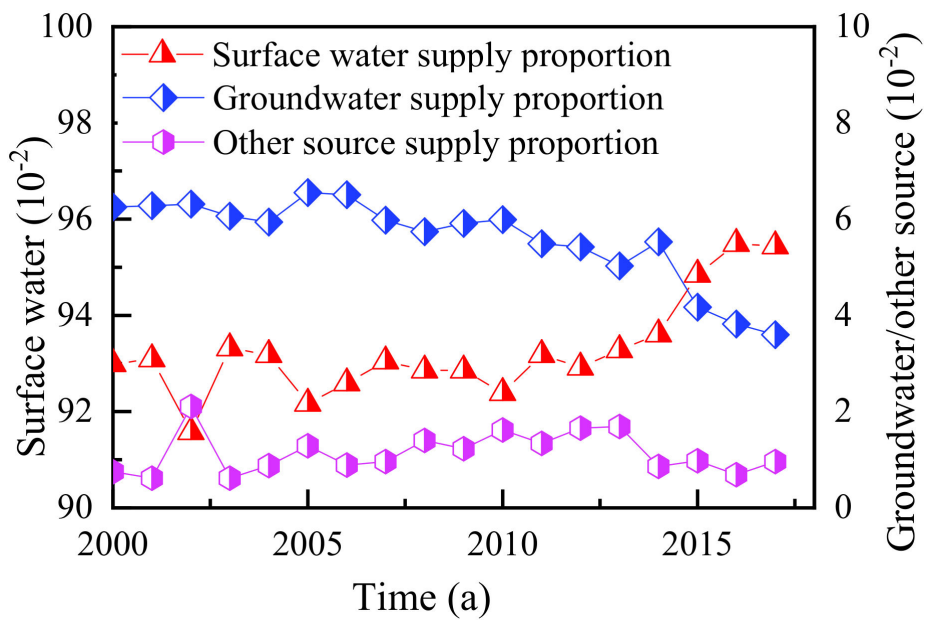

Figure 12. Historical water supply structure in upstream Yangtze River.

\subsubsection{Analysis of Surface Water Supply Capacity in Upstream Yangtze River}

According to the data of the National Comprehensive Plan for Water Resources [48] compiled in 2008 and the Changjiang and Southwest Rivers Water Resources Bulletin in 2000 [45], the water supply capacity and the actual amount of supplied water in the Yangtze River Basin in 2000 are shown in Table 2.

As shown in Table 2, the average utilization rate of surface water supply projects was $82 \%$ in the entire Yangtze basin in 2000; upstream, it was $87 \%$, over $80 \%$ of which comprised the utilization rates of all tributaries in the upstream sub-basins excluding the Jinsha River Basin (71\%). Due to the lack of statistical data for new water supply projects upstream between 2000 and 2015, the water supply capacity in 2015 in this basin was estimated according to the actual supply amount and utilization rate. The surface water supply capacity of the Yangtze River Basin was $134 \mathrm{Bm}^{3}$ in 1980, of which $26.2 \mathrm{Bm}^{3}$ was in the upstream basin [48]. Compared with 1980, the water supply capacity in the whole basin and upstream basin respectively increased by $67.2 \mathrm{Bm}^{3} \mathrm{~m}$ and $13.4 \mathrm{Bm}^{3}$ in 2000 , accounting for about $50 \%$ of that recorded in the 1980s. The period from 2001 to 2015 
was also characterized by significant water conservancy development. During this period, several water conservancy projects of varying scopes were initiated or completed in the upstream Yangtze River, and the water supply capacity was significantly improved. From this information, it was estimated that the utilization rate of surface engineering in 2015 was slightly higher than that in 2000, and that of upstream comprehensive water supply engineering would reach approximately $88 \%$ in 2015.

Based on the actual water supply in each sub-basin in 2015, the water supply capacity of the surface water supply project in the upstream Yangtze River was calculated, as shown in Table 3.

Table 2. Water supply capacity and actual supply amount in Yangtze River Basin in $2000\left(\mathrm{Bm}^{3}\right)$.

\begin{tabular}{|c|c|c|c|c|c|c|c|c|c|}
\hline \multirow{2}{*}{ Water System } & \multicolumn{2}{|c|}{$\begin{array}{l}\text { Supply Capacity of Large } \\
\text { or Middle Reservoirs }\end{array}$} & \multicolumn{4}{|c|}{ Capacity of Other Water Supply Project } & \multirow{2}{*}{$\begin{array}{c}\text { Total } \\
\text { Capacity }\end{array}$} & \multirow{2}{*}{$\begin{array}{l}\text { Actual } \\
\text { Supply }\end{array}$} & \multirow{2}{*}{$\begin{array}{l}\text { Utilization } \\
\text { Rate }\end{array}$} \\
\hline & Number & Capacity & $\begin{array}{c}\text { Small } \\
\text { Reservoir }\end{array}$ & Pond & Diversion & Lifting & & & \\
\hline Jinsha river & 63 & 1.23 & 1.37 & 0.31 & 3.85 & 1.73 & 8.49 & 6.06 & $71 \%$ \\
\hline Mintuo river & 39 & 0.87 & 0.91 & 0.74 & 7.00 & 1.74 & 11.47 & 11.47 & $100 \%$ \\
\hline Jialing river & 61 & 1.54 & 1.1 & 1.31 & 1.42 & 2.81 & 8.18 & 6.64 & $81 \%$ \\
\hline Wujiang river & 26 & 1.22 & 1.02 & 0.13 & 0.96 & 1.13 & 4.46 & 3.92 & $88 \%$ \\
\hline Yiban to Yichang & 30 & 0.32 & 1.08 & 0.87 & 0.95 & 3.79 & 7.01 & 6.17 & $88 \%$ \\
\hline Dongting lake & 284 & 7.62 & 6.16 & 5.16 & 7.25 & 12.32 & 38.51 & 33.54 & $87 \%$ \\
\hline Hanjiang river & 144 & 5.11 & 0.76 & 1.37 & 4.69 & 4.11 & 16.04 & 11.12 & $69 \%$ \\
\hline Yichang to Hukou & 153 & 5.05 & 1.55 & 1.9 & 4.49 & 6.95 & 19.94 & 16.47 & $83 \%$ \\
\hline Poyang lake & 210 & 4.65 & 4.16 & 1.61 & 5.06 & 7.07 & 22.55 & 19.22 & $85 \%$ \\
\hline Taihu lake & 20 & 0.51 & 0.16 & 0.24 & 10.47 & 26.21 & 37.59 & 34.66 & $92 \%$ \\
\hline Below Hukou & 76 & 2.78 & 1.12 & 3.45 & 10.62 & 9 & 26.97 & 14.81 & $55 \%$ \\
\hline Upstream & 219 & 5.18 & 5.48 & 3.36 & 14.18 & 11.2 & 39.61 & 34.27 & $87 \%$ \\
\hline $\begin{array}{l}\text { Middle and } \\
\text { downstream }\end{array}$ & 887 & 25.72 & 13.91 & 13.73 & 42.58 & 65.66 & 161.6 & 129.82 & $80 \%$ \\
\hline Entire Yangtzi River & 1106 & 30.90 & 19.39 & 17.09 & 56.76 & 76.86 & 201.21 & 164.09 & $82 \%$ \\
\hline
\end{tabular}

Table 3. Water supply capacity estimation in sub-basins of upstream Yangtze River in 2015.

\begin{tabular}{ccccc}
\hline Sub-Basin & Utilization Rate & $\begin{array}{c}\text { Actual Supply } \\
\mathbf{( B m}^{\mathbf{3}} \mathbf{)}\end{array}$ & Capacity $\mathbf{( B m}^{\mathbf{3}} \mathbf{)}$ & $\begin{array}{c}\text { Cumulative } \\
\text { Capacity } \mathbf{( B m}^{\mathbf{3}} \mathbf{)}\end{array}$ \\
\hline Shigu & $80 \%$ & 0.54 & 0.67 & 0.67 \\
Panzhihua & $80 \%$ & 0.83 & 1.04 & 1.71 \\
Xiluodu & $80 \%$ & 2.77 & 3.46 & 5.17 \\
Xiangjiaba & $80 \%$ & 0.24 & 0.30 & 5.47 \\
Zhutuo & $90 \%$ & 13.76 & 15.29 & 20.76 \\
Cuntan & $85 \%$ & 7.34 & 8.64 & 29.40 \\
Yichang & $90 \%$ & 17.34 & 19.27 & 48.66 \\
Upstream & $88 \%$ & 42.82 & 48.66 & 48.66 \\
Yangtze River & $88 \%$ & & \\
\hline
\end{tabular}

\subsection{Water Demand Forecasting}

Water diversion and use are interactions between human activity and the natural water cycle, comprising two essential methods by which humans affect water systems. Therefore, the intensity and evolution of human activity should be considered in water demand forecasting.

\subsubsection{Change Analysis of Social-Economic Factors}

Social-economic planning or macro regulation targets were collected and combined with historical data to develop stage control indices and forecast long-term socioeconomic changes based on the data in 2015. The control indices include future population, livestock population, irrigated farmland area, forestry and grassland, replenished fishery area, and industrial production. Considering the difference in domestic water use between rural and urban areas, and the differences in large and small livestock populations, the socioeconomic factors of domestic water use were divided into urban, rural, large livestock, and small 
livestock. The number of livestock was expected to vary with population, regardless of exports and the changes in per-capita demand for meat products. The irrigated farmland area refers to the farmland area that can be irrigated normally under certain conditions of water source and irrigation facilities and is limited to the total cultivated land area. In recent years, the growth of forestry and fisheries in China has been relatively flat. The irrigated areas of forestry, grassland, and replenishment areas are all kept constant by the limitation of the total land area. According to China's "13th Five-year Plan" [49], industrial development will exhibit steady growth in the coming years. As the forecast period is 2016-2100, the control period was selected as 2016-2020, 2020-2030, 2030-2050, and 2050-2100. According to the "13th Five-year Social-economic Development Plan" of China, river basin, and local governments, a "centennial goal" of China's economic growth [50], and other related planning and management goals, the control indices applicable to the basin were set as shown in Table 4. Current and historical data were taken from the national and local statistics bureaus and the Statistical Bulletin of National Economic and Social Development.

Table 4. Social-economic control years and indices.

\begin{tabular}{|c|c|c|c|c|c|c|}
\hline Prediction Index & Control Year & 2015 & 2020 & 2030 & 2050 & 2100 \\
\hline \multirow{2}{*}{ Urban / rural population } & Growth rate of total population $/ \%$ & 0.5 & 0.43 & & -0.43 & -0.54 \\
\hline & Urbanization rate $/ \%$ & 43 & 48 & 58 & 75 & 95 \\
\hline Irrigated Area of farmland & Irrigated ratio of farmland $/ \%$ & 35 & & 45 & 55 & 55 \\
\hline \multirow{3}{*}{ Industrial product } & GDP growth rate in China /\% & 9 & 6 & 4 & 3 & 1.5 \\
\hline & GDP growth rate in the basin/\% & 10 & 7 & 5 & 4 & 1.5 \\
\hline & Industrial production growth rate $/ \%$ & 5 & 3.5 & 2.5 & 2 & 0.5 \\
\hline
\end{tabular}

According to the base value of socioeconomic factors and the current level of economic development in each sub-basin, control indices were pushed forward or backward to obtain the predicted values of the future factors in each sub-basin. The changes in socioeconomic factors in the Shigu section are shown in Figure 13 as an example.

\subsubsection{Change Forecasting of Water Use Indices}

Owing to a strong emphasis on development, utilization, and protection of water resources, China has formulated various water-related plans at different levels [48,51]. Similar to socioeconomic indicators, the water use planning and regulation targets of the study area were collected and considered in combination with the historical data of national and local water resources bulletin $[45,46]$ to develop appropriate staging control indicators. Then, long-term comprehensive water use indices were predicted based on 2015 data. The predicted indices include the future domestic water use index; livestock water use index; EUC of irrigation water; comprehensive irrigation/replenish index for farmland, forestry, grassland, and fishery; and industrial water demand per 1000-yuan production. Considering the current level of domestic water use, even if the awareness of water conservation is constantly strengthened, the domestic water use index will be significantly increased with the improvement of living standards, and the livestock water use index will remain unchanged. The comprehensive irrigation/replenish indices for agriculture, forestry, grassland, and fishery were calculated by planting distribution, net irrigation quota for each crop, and EUC of irrigation in the study area. The growth rate of EUC for irrigation water decreases as its value increases. The reuse rate of industrial water is an important index for industrial water-use level and water-conservation level, and industrial water demand per 1000-yuan production was calculated. The control period is consistent with social-economic indicators. The overall control indices of the upstream basin are set according to the 13th five-year plan for water conservancy development and reform and for building a water-conserving society planning of China [51,52] and local governments and other relevant planning and management goals, as shown in Table 5. 
Current and historical data were obtained from national, local, and river basin water quota standards and the water resources bulletin [45].

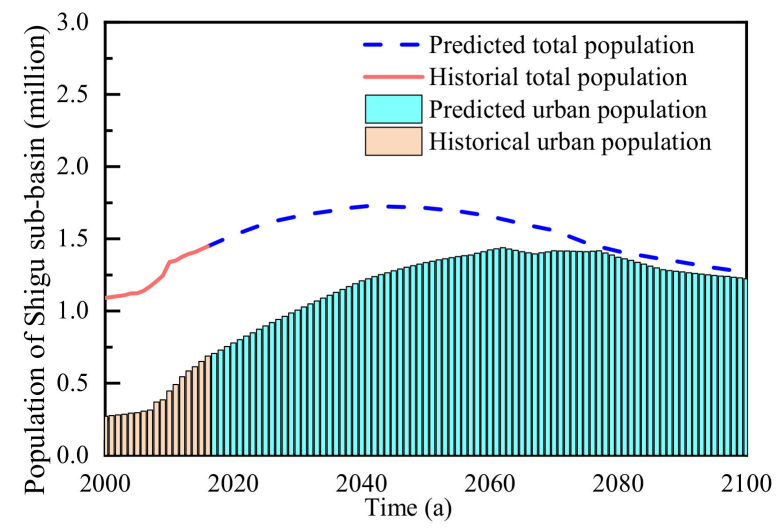

(a)

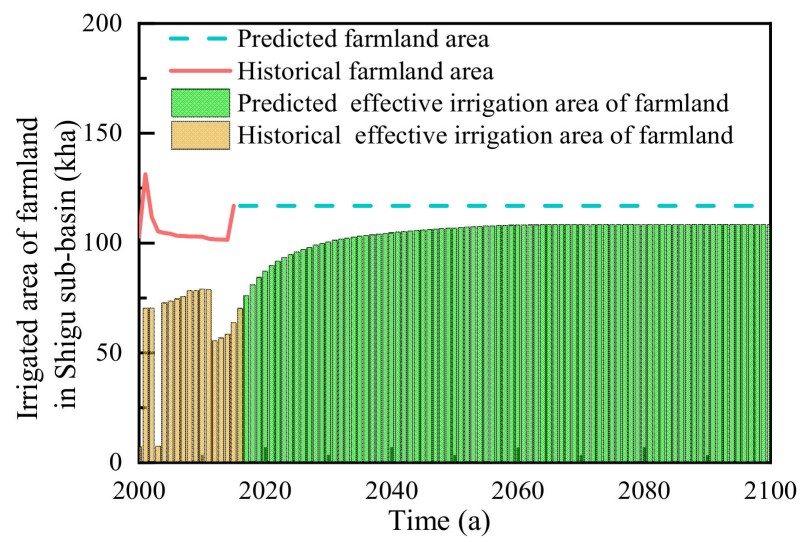

(c)

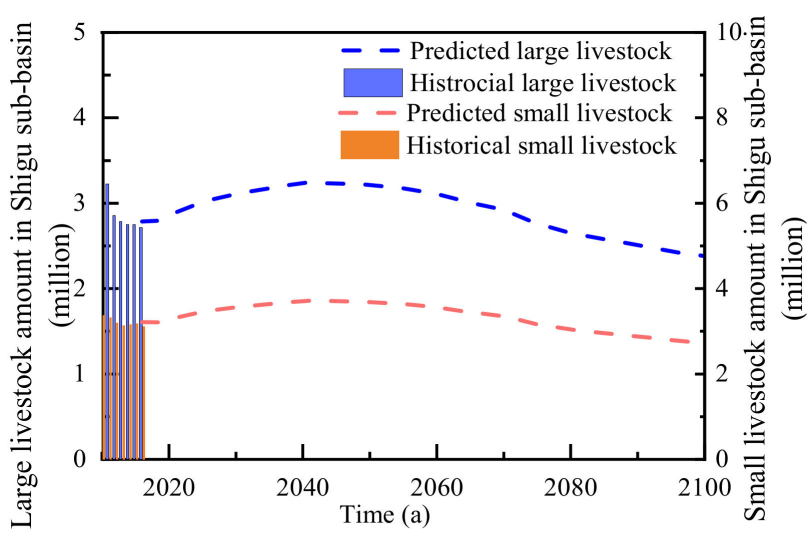

(b)

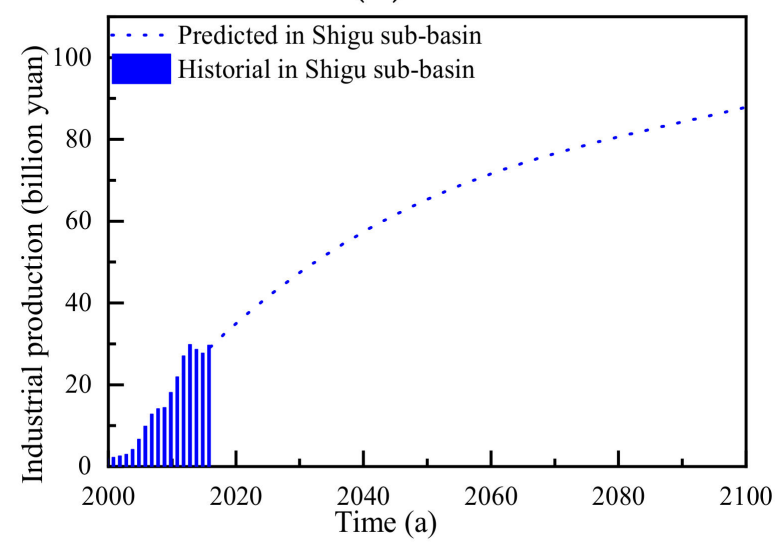

(d)

Figure 13. Social-economic factors forecasting in Shigu section: population (a), livestock (b), irrigated area (c), and industrial production $(\mathbf{d})$.

Table 5. Social-economic control years and indices.

\begin{tabular}{cccccc}
\hline Index Time Point & \multirow{2}{*}{$\mathbf{2 0 1 5}$} & \multirow{2}{*}{$\mathbf{2 0 2 0}$} & $\mathbf{2 0 3 0}$ & $\mathbf{2 0 5 0}$ & $\mathbf{2 1 0 0}$ \\
\hline Annual growth of urban domestic water $/ \mathrm{L}$ & 2 & 2 & 2 & 1.5 & 1.5 \\
Annual growth rate of rural domestic water $/ \mathrm{L}$ & 1 & 1 & 1 & 1 & 1 \\
EUC for irrigation & 0.5 & 0.54 & 0.6 & 0.7 & 0.875 \\
Industrial water use per 1000-yuan production $/ \mathrm{m}^{3}$ & 11.8 & 7 & 5.6 & 3 & 1.5 \\
Reuse rate of industrial water $/ \%$ & 72 & & 86 & 90 & 95 \\
\hline
\end{tabular}

According to the base value of water indices in 2015 and the current level of water use, comprehensive water use indices in 2016-2100 in the study area were predicted, as shown in Figure 14.

\subsubsection{Water Demand Forecast}

Based on the results presented in Sections 4.3.1 and 4.3.2, the water demand under runoff frequencies of $50 \%, 75 \%$, and $95 \%$ from 2016 to 2100 was calculated according to Formulas (2)-(8). Figures 15 and 16 show the changes in domestic and total water demand under different runoff frequencies in each sub-basin. 


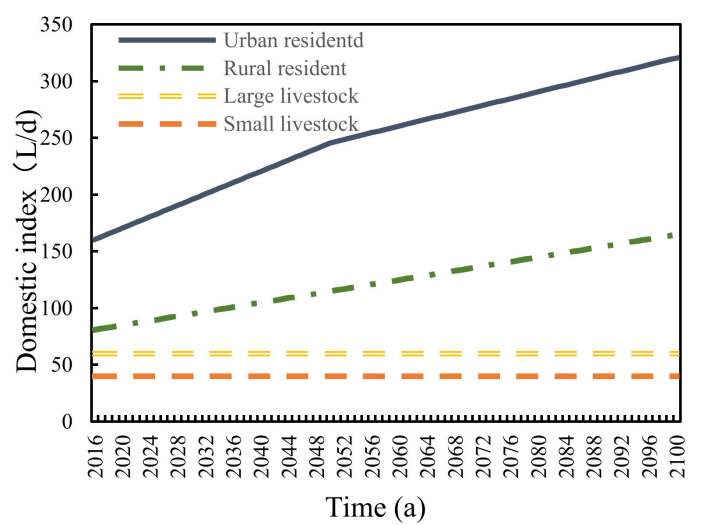

(a)

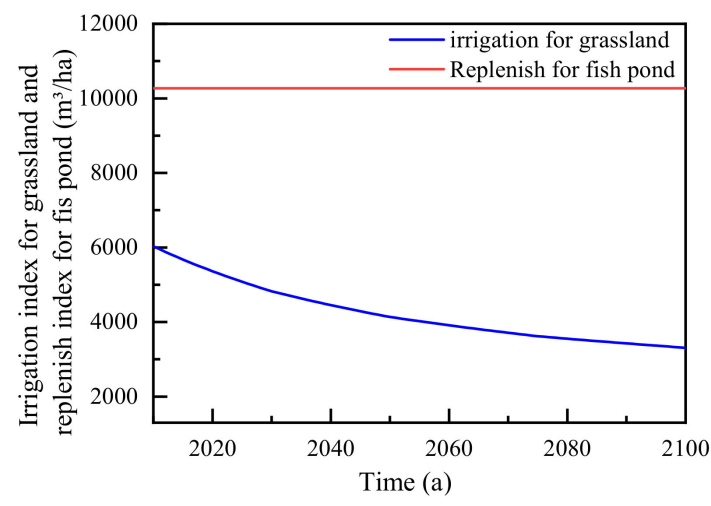

(c)

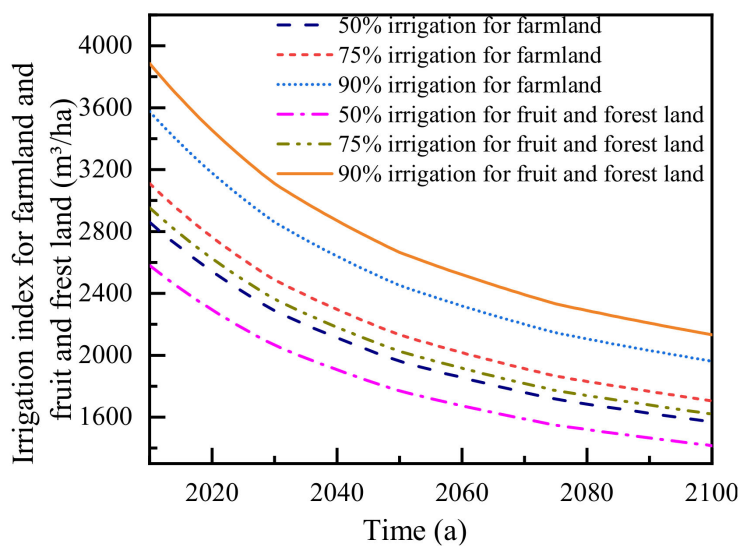

(b)

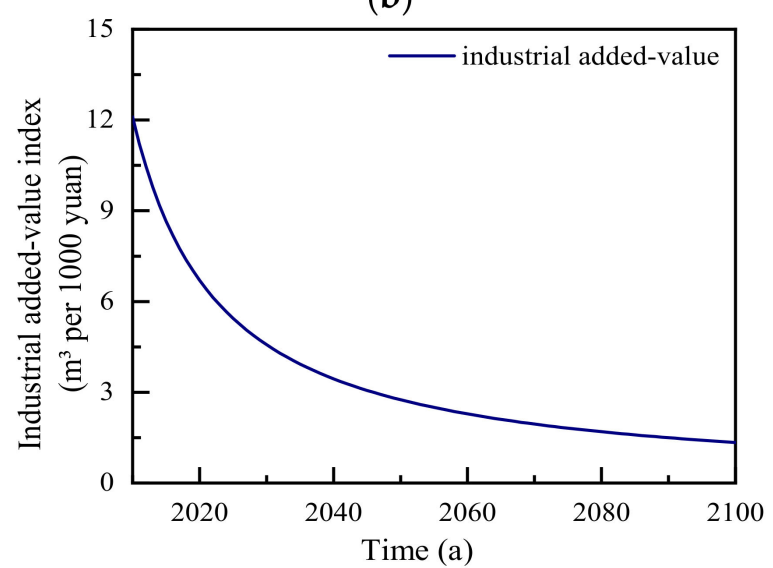

(d)

Figure 14. Forecasting of water use indices: domestic (a), agricultural forestry and pastoral and fishery irrigation/replenishment $(\mathbf{b}, \mathbf{c})$, and industrial $(\mathbf{d})$.
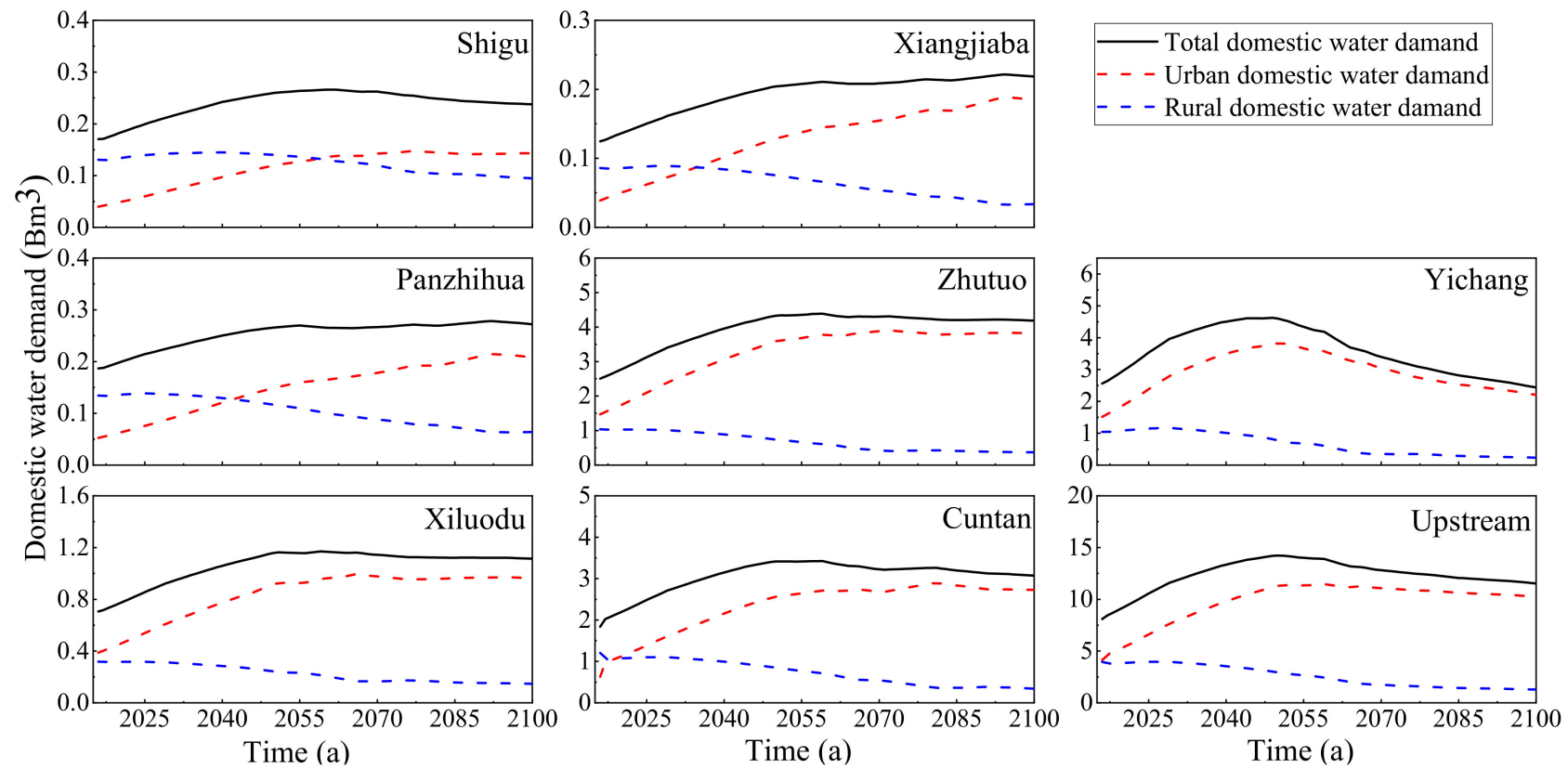

Figure 15. Domestic water demand forecasting in each sub-basin. 

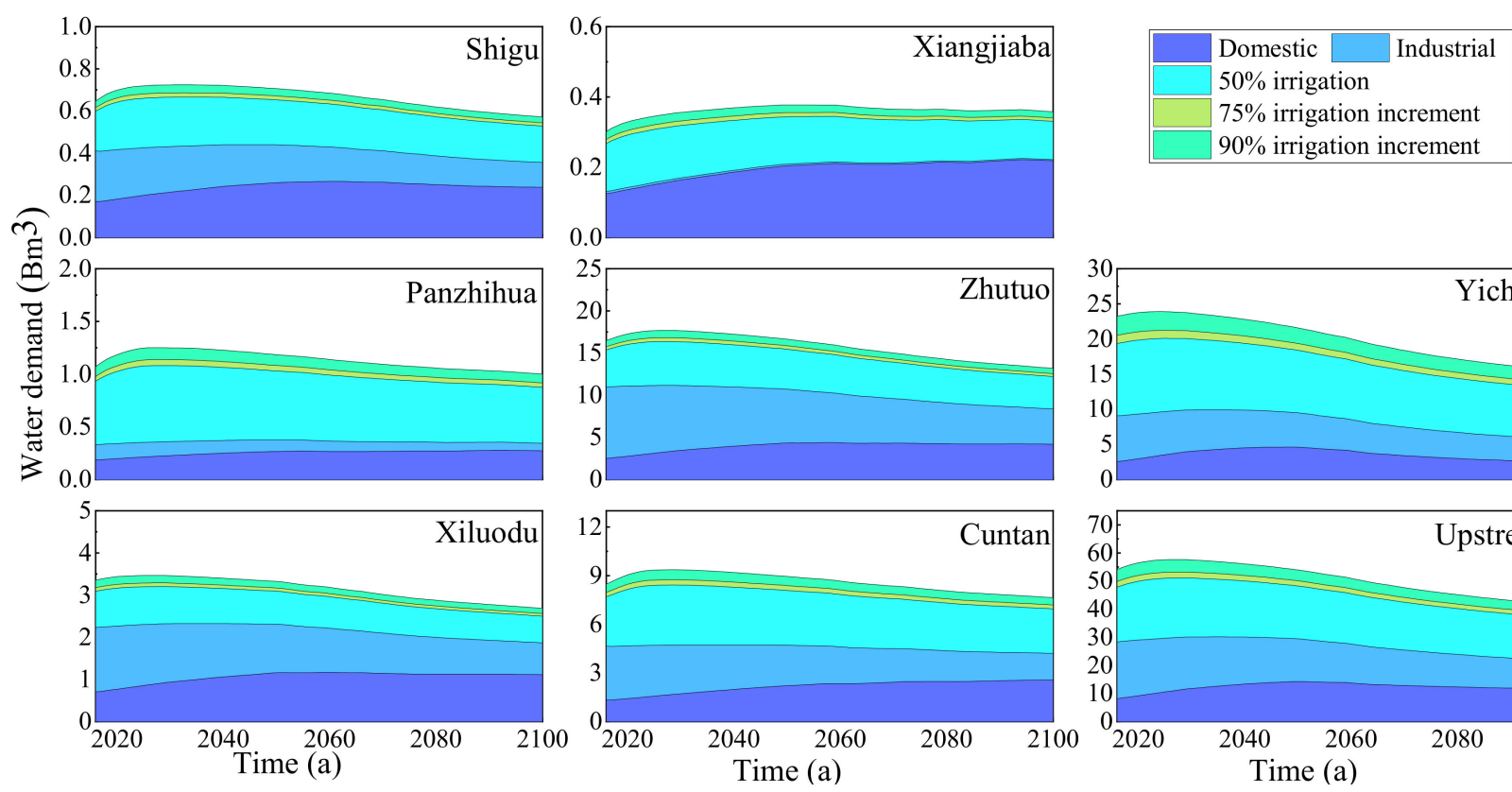

$75 \%$ irrigation increment

$90 \%$ irrigation increment

Figure 16. Forecasting of water demand in upstream Yangtze River and its sub-basins.

According to Figures 15 and 16, the proportion of agricultural demand will decrease from 2016 to 2100 in the upstream Yangtze River Basin; as the proportion of domestic demand increases, the demand structure of the water resource coupling system will gradually improve.

Domestic water demand in sub-basins exhibited two primary trends from 2016 to 2100 - first rising, then falling and rising. Among them, the sub-basins of Shigu, Xiluodu, Zhutuo, Cuntan, and Yichang tended to follow the first trend, with the peak of domestic demand appearing around 2050, while the other exhibited the second trend, exhibiting a reduction in the rate of increase after 2050. The intercoupling of the change in population, which first increases and then decreases in the long term in the future, and the continuous improvement of people's quality of life results in domestic water demand changes in sub-basins.

The industrial water demand gradually decreases from 2016 to 2100 in the sub-basins. While industrial production continues to increase, the decrease in industrial water demand reflects the increasing reuse rate of industrial water and the gradual improvement in industrial technology owing to continued technological development. However, agricultural water demand showed a trend of first rising and then falling, reaching a peak between 2025 and 2035, which was a result of the comprehensive effect of two factors: increasing irrigation area and improving EUC of irrigation water. Due to the limitation of the land area, the first factor will eventually remain constant. The second continues to increase with the gradual application of new irrigation technologies, such as drip irrigation, replacing flood irrigation characterized by high water demand and environmental cost. The agricultural irrigation demand will eventually remain stable at a lower level.

In terms of the total water demand, the six sub-basins except Xiangjiaba show a trend of first rising and then falling, reaching the peak of water demand around 2030. Because of the high domestic water demand and stable demand structure in the Xiangjiaba sub-basin, its total water demand reaches its peak around 2050 and then declines slowly. The peak of the total water demand for each sub-basin is shown in Table 6. 
Table 6. Peak water demand in upstream Yangtze River and sub-basins from 2016 to 2100.

\begin{tabular}{|c|c|c|c|c|c|c|}
\hline \multirow{2}{*}{ Sub-Basin } & \multicolumn{2}{|c|}{$50 \%$ Runoff Frequency } & \multicolumn{2}{|c|}{$75 \%$ Runoff Frequency } & \multicolumn{2}{|c|}{$90 \%$ Runoff Frequency } \\
\hline & Peak Demand $\left(\mathrm{Bm}^{3}\right)$ & Time & Peak Demand $\left(\mathrm{Bm}^{3}\right)$ & Time & Peak Demand $\left(\mathrm{Bm}^{3}\right)$ & Time \\
\hline Shigu & 6.66 & 2033 & 6.86 & 2032 & 7.24 & 2032 \\
\hline Panzhihua & 10.81 & 2028 & 11.37 & 2028 & 12.51 & 2027 \\
\hline Xiluodu & 32.03 & 2029 & 32.89 & 2029 & 34.68 & 2027 \\
\hline Xiangjiaba & 3.45 & 2059 & 3.65 & 2059 & 3.77 & 2050 \\
\hline Zhutuo & 163.64 & 2027 & 168.19 & 2027 & 176.77 & 2027 \\
\hline Cuntan & 94.75 & 2034 & 97.96 & 2034 & 104.07 & 2034 \\
\hline Yichang & 200.9 & 2025 & 212.38 & 2025 & 238.98 & 2024 \\
\hline Upstream & 511.35 & 2029 & 532.06 & 2029 & 576.22 & 2028 \\
\hline
\end{tabular}

\subsection{Supply Versus Demand Analysis}

\subsubsection{Supply Capacity Limitation}

According to the runoff simulation results and water demand forecasting results in comparison with the current water supply capacity in each sub-basin, the supply and demand contradictions of the water resource coupling system limited by the supply capacity in sub-basins of the upstream Yangtze River were determined, as shown in Figure 17.
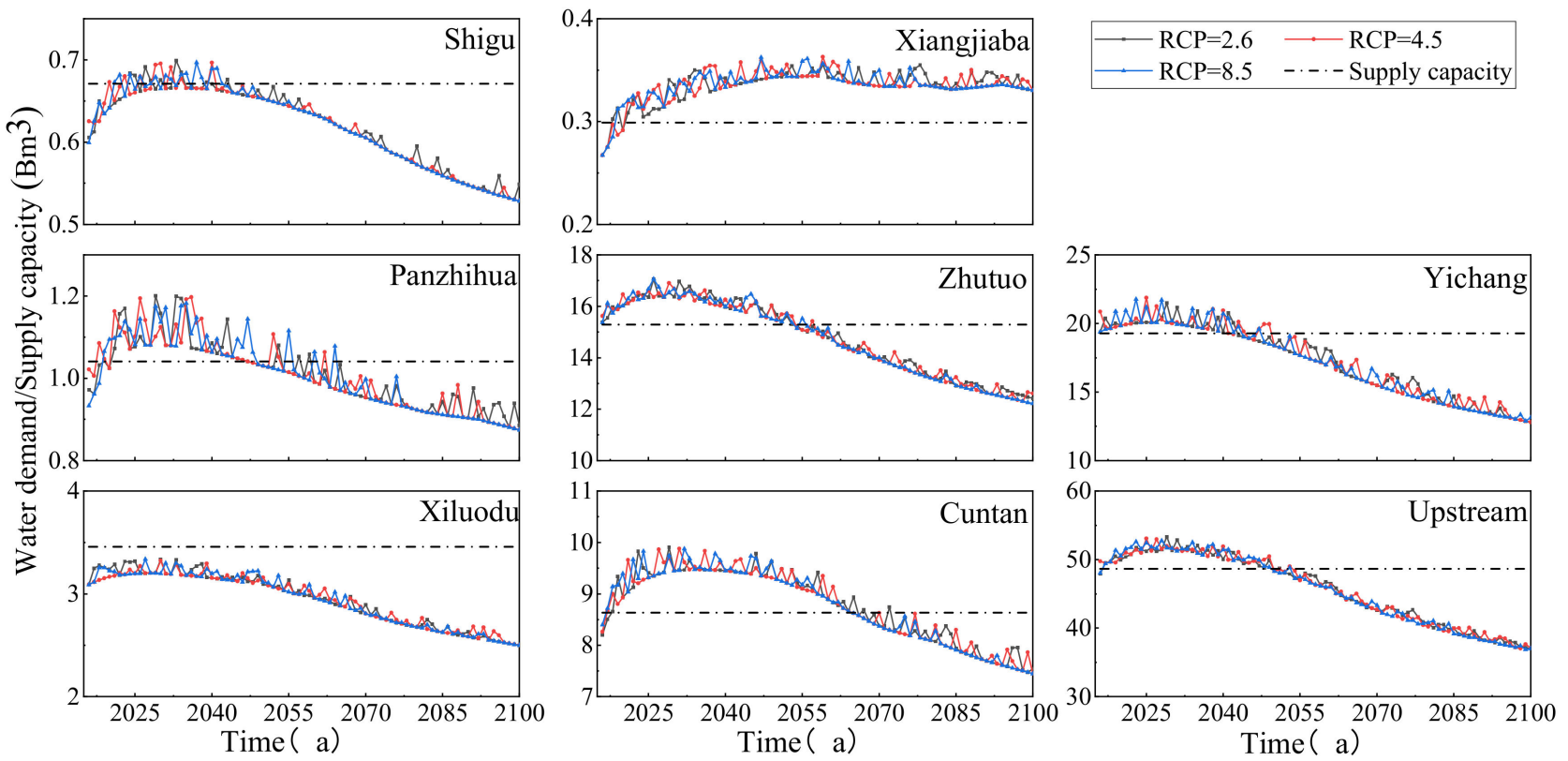

Figure 17. Contradiction evolution under supply capacity limitation in each sub-basin.

Figure 17 shows that if the current water supply capacity remains unchanged, the upstream Yangtze River Basin will face a contradiction limited by supply capacity between 2020 and 2050. Only the existing water supply capacity of the Xiluodu sub-basin is higher than its predicted water demand and will not face this contradiction. Different degrees of this contradiction will appear in the Shigu sub-basin from 2020 to 2040; in the Panzhihua, Zhutuo, and Yichang sub-basins from 2020 to 2050; in the Cuntan sub-basin from 2020 to 2065; and in the Xiangjiaba sub-basin around 2020. This contradiction between supply and demand mainly occurs between 2020 and 2050 and gradually decreases after 2050 , which can be alleviated by adding new water supply projects or increasing project supply capacities. 


\subsubsection{Ecological Condition Limitation}

To achieve correspondence with the simulated runoff value, the predicted data of water demand were superimposed when the proportion of water demand in the runoff above each section was calculated (hereinafter referred to as the water demand ratio). The difference between the water demand ratio and threshold coefficient reflects the contradiction between water demand and utilizable surface water resources, i.e., the contradiction between water supply and ecological and environmental conditions. It was considered that the mismatch between the demand and stress coefficient causes a minor contradiction, and the mismatch between the demand and damage coefficient causes a severe contradiction. The area above one section indicates the summary of sub-basins above that section. Figure 18 shows the annual water demand ratio in the areas above each section.
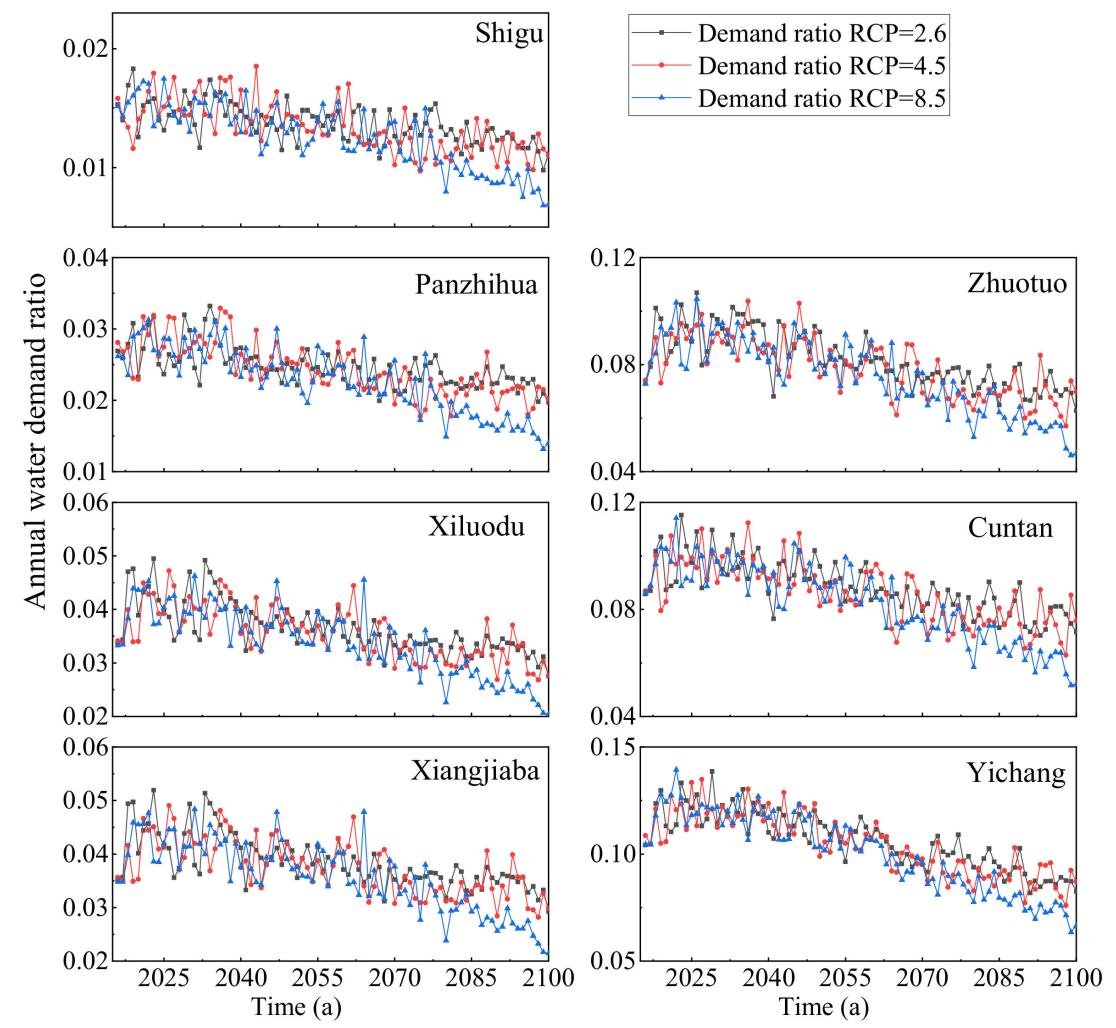

Figure 18. Annual water demand ratio above control sections.

Figure 18 indicates that the water demand ratio above each section does not exceed the stress threshold coefficient 0.2 throughout the year and gradually increases from upstream to downstream. According to the annual calculation results, the water stress in the upstream Yangtze River increases gradually from the top to the bottom, but no contradiction will be limited by the ecological environment in the next 85 years.

However, owing to the uneven distribution of runoff and water demand in a given year, the contradiction between monthly supply and demand may be more prominent. Taking RCP4.5 as an example, the relationship between the monthly water demand ratio and the threshold coefficient above each section was calculated, as shown in Figure 19. The invisibility of the threshold coefficient in some figures indicates that the upper limit of the water demand ratio is far lower than the threshold coefficient in the following figures. 

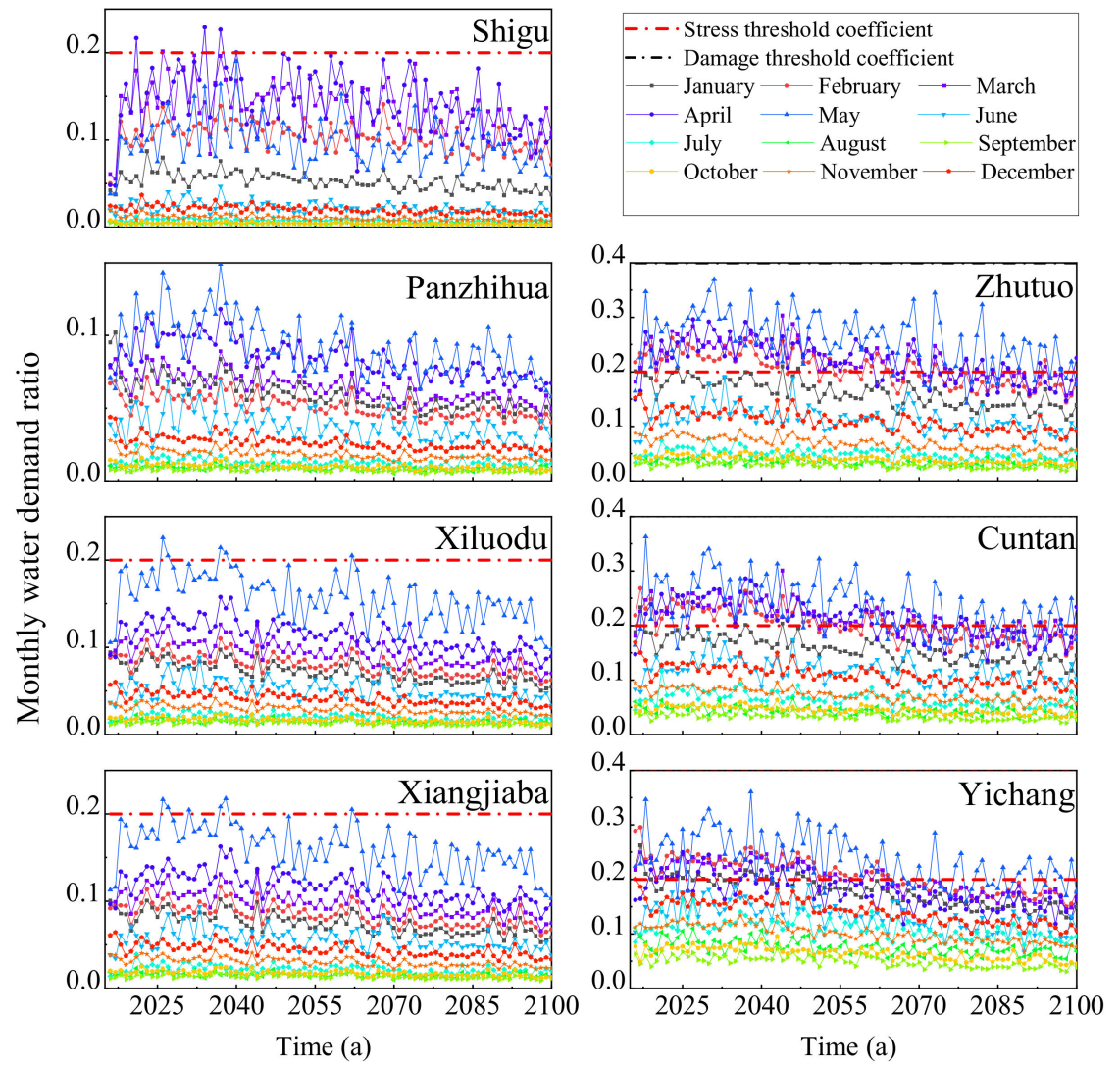

Figure 19. Monthly contradiction evolution under ecological limitation above each section.

Figure 19 shows that the monthly water demand ratio exceeded the stress threshold coefficient above all sections except Panzhihua, and the damage threshold coefficient was nearly reached over several months in the areas above the Zhutuo, Cuntan, and Yichang sections. Taking the Xiangjiaba section as a boundary, minor contradictions were observed in March, April, and May above Shigu, Panzhihua, and Xiluodu sections. The peak water demand ratio in these areas was observed around 2040 and is expected to decrease after 2050 following the decrease in water demand. In addition, contradictions are expected in January, February, March, April, and May above the Zhutuo, Cuntan, and Yichang sections and will remain, among which severe contradiction nearly appear in May around 2030 above the Zhutuo section, around 2020 above the Cuntan section, and around 2040 above the Yichang section or in the whole upstream Yangtze River Basin.

\section{Conclusions}

A climate model was introduced, and development plans/data of local socioeconomic/water use indicators were collected to systematically forecast the water supply and demand pattern and its changes in the coupled water resources system of the upstream Yangtze River over the next 85 years. By analyzing the historical water supply structure of the water coupling system of the study area, the main water supply source in this basin was identified as surface water. Considering the different influences onwater supply and demand patterns, the utilizable water resources and supply capacity were evaluated as preparation. The utilizable water resources are determined by simulated runoff and water utilization threshold. Comprehensively considering the influence of water use mechanism and macro regulation on future water use change, the classified index method under macro regulation was used to extend the forecasting period and construct a long-term water demand forecasting model. Further, contradiction analysis was conducted in terms of water supply capacity and ecological condition limitations. It was found that the simulated runoff increased slightly under different RCPs; the water demand generally showed a trend 
of first increasing and then decreasing; the contradiction between supply and demand was more prominent on a monthly basis than on annual basis and became obvious gradually from top to bottom in the study area for the next 85 years.

The water use situation in the upstream Yangtze River was analyzed systematically from two aspects of water supply and demand under the changing environment of climate change and socioeconomic development. Compared with data-driven models, the water demand model based on the relationship between socioeconomic factors and water use is less reliant on historical data of water use and more feasible for long-term forecasting, especially in China, where macro regulation policies could provide socioeconomic scenarios for the future. It provides an overview of the water demand in the long term under the scenario that society and economy develop as planned. This study provided a longer forecast period than other studies on the water supply and demand. A large number of socioeconomic plans and water use data were collected, and the water use situation and its changes in further future were explored, which can be used as references for the water resources management agencies to develop future water management plans or policies about the upstream Yangtze River Basin.

There are also many points that could be further improved. Short-term forecasting of water demand, which are more accurate, would be conducted in further study to develop a water supply and demand pattern analysis system coupled with long-medium-short-term forecast. And the relationship between local environment condition and its environmental water use (in channels) also remains to be explored.

Author Contributions: L.M. revised the first draft of the article. S.L. carried out experiments and wrote the first draft of the paper. J.Z. and Y.W. provided useful advice and made some corrections. W.H. prepared raw data for this paper. All authors have read and agreed to the published version of the manuscript.

Funding: This work was supported by the National Natural Science Foundation of China (No. 51979114 \& No. 51479075), the Fundamental Research Funds for the Central Universities (No. 2017KFYXJJ199) and Open Foundation of State Key Laboratory of Hydrology-Water Resources and Hydraulic Engineering (2014491811).

Institutional Review Board Statement: Not applicable.

Informed Consent Statement: Not applicable.

Data Availability Statement: The data used to support the findings of this study are available from the corresponding author upon request.

Acknowledgments: Special thanks are given to the anonymous reviewers and editors for their constructive comments.

Conflicts of Interest: The authors declare no conflict of interest.

\section{References}

1. Chen, Z.J. The strategic position and the ecological and environmental function of the upper reaches of the Yangtze river. Mt. Res. 2000, 18, 258-262.

2. Li, Q.; Cheng, G.D.; Shen, Y.P. Climate Change and Its Impact on the Eco-environment in the Source Regions of the Yangtze and Yellow Rivers in recent 40 years. J. Glaciol. Geocryol. 2001, 23, 346-352.

3. Jiao, D.L.; Wang, D.J.; Lv, H.Y. Effects of human activities on hydrological drought patterns in the Yangtze River Basin, China. Nat. Hazards 2020, 104, 1111-1124. [CrossRef]

4. Qu, S.; Wang, L.C.; Lin, A.W.; Zhu, H.J.; Yuan, M.X. What drives the vegetation restoration in Yangtze River basin, China: Climate change or anthropogenic factors? Ecol. Indic. 2018, 90, 438-450. [CrossRef]

5. Huang, C.B.; Teng, M.J.; Zeng, L.X.; Zhou, Z.X.; Wang, P.C. Long-term changes of land use/cover in the Three Gorges Reservoir Area of the Yangtze River, China. Chin. J. Appl. Ecol. 2018, 29, 1585-1596.

6. Dai, M.L. Hydrological Regime Changes Considering Mega Reservoirs in Upper Yangtze River Basin; Huazhong University of Science \& Technology: Wuhan, China, 2017.

7. Ran, R.P. On the Coordinative Development of Environment and Economy in the Upper Reaches of Yangtze River; Southwest University: Chongqing, China, 2003. 
8. Gonzalez, P.; Neilson, R.P.; Lenihan, J.M.; Drapek, R.J. Global patterns in the vulnerability of ecosystems to vegetation shifts due to climate change. Glob. Ecol. Biogeogr. 2010, 19, 756-768. [CrossRef]

9. Meinshausen, M.; Smith, S.J.; Calvin, K.; Daniel, J.S.; Kainuma, M.L.T.; Lamarque, J.; Matsumoto, K.; Montzka, S.A.; Raper, S.C.B.; Riahi, K.; et al. The RCP greenhouse gas concentrations and their extensions from 1765 to 2300. Clim. Chang. 2011, 109, 213. [CrossRef]

10. Taylor, K.E.; Stouffer, R.J.; Meehl, G.A. An overview of CMIP5 and the experiment design. Bull. Am. Meteorol. Soc. 2012, 93, 486-498. [CrossRef]

11. Siew, J.H.; Tangang, F.T.; Juneng, L. Evaluation of CMIP5 coupled atmosphere-ocean general circulation models and projection of the Southeast Asian winter monsoon in the 21st century. Int. J. Climatol. 2014, 34, 2872-2884. [CrossRef]

12. Mimikou, M.A.; Baltas, E.; Varanou, E.; Pantazis, K. Regional impacts of climate change on water resources quantity and quality indicators. J. Hydrol. 2000, 234, 96-109. [CrossRef]

13. Tung, C.P.; Haith, D.A. Global-Warming effects on new york streamflows. J. Water Resour. Plan Manag. 1995, 121, 216-225. [CrossRef]

14. Matondo, J.I.; Peter, G.; Msibi, K.M. Evaluation of the impact of climate change on hydrology and water resources in Swaziland: Part II. Phys. Chem. Earth 2004, 29, 1193-1202. [CrossRef]

15. Li, L.; Hao, Z.C.; Wang, J.H.; Wang, Z.H.; Yu, Z.B. Impact of future climate change on runoff in the head region of the Yellow River. J. Hydrol. Eng. 2008, 13, 347-354. [CrossRef]

16. He, Z.L. Climate Change Impacts on Stream Flow of the Upper San Joaquin River Headwater Watershed California, America; Northwest A\&F University: Xianyang, China, 2012.

17. Ekins, P. The Kuznets curve for the environment and economic growth: Examining the evidence. Environ. Plan A 1997, 29, 805-830. [CrossRef]

18. Katz, D. Water use and economic growth: Reconsidering the Environmental Kuznets Curve relationship. J. Clean. Prod. 2015, 88, 205-213. [CrossRef]

19. Aitken, C.K.; Duncan, H.; McMahon, T.A. A cross-sectional regression analysis of residential water demand in Melbourne, Australia. Appl. Geogr. 1991, 11, 157-165. [CrossRef]

20. Sebri, M. Forecasting urban water demand: A meta-regression analysis. J. Environ. Manag. 2016, 183, 777-785. [CrossRef]

21. Yasar, A.; Bilgili, M.; Simsek, E. Water Demand Forecasting Based on Stepwise Multiple Nonlinear Regression Analysis. Arab. J. Sci. Eng. 2012, 37, 2333-2341. [CrossRef]

22. Jing, Y.P.; Xin, Z.; Yan, L. Forecasting of urban water demand based on combining Grey and BP neural network with Markov chain model. J. Northwest A F Univ. 2011, 39, 229-234.

23. Guo, F.Q. Prediction of City Industrial Water Demand Based on Grey GM $(1,1)$ model. Ground Water. 2010. Available online: https:/ / en.cnki.com.cn/Article_en/CJFDTotal-DXSU201003045.htm (accessed on 24 April 2020).

24. Wa, D.A. Application of Gray Model to Prediction of Water Demand in Tibet. China Water Wastewater. 2010. Available online: https:/ / en.cnki.com.cn/Article_en/CJFDTotal-GSPS201001017.htm (accessed on 24 April 2020).

25. Campisi-Pinto, S.; Adamowski, J.; Oron, G. Forecasting Urban Water Demand Via Wavelet-Denoising and Neural Network Models. Case Study: City of Syracuse, Italy. Water Resour. Manag. 2012, 26, 3539-3558. [CrossRef]

26. Kofinas, D.; Papageorgiou, E.; Laspidou, C.; Mellios, N.; Kokkinos, K. Daily multivariate forecasting of water demand in a touristic island with the use of artificial neural network and adaptive neuro-fuzzy inference system. In Proceedings of the 2016 International Workshop on Cyber-physical Systems for Smart Water Networks, CySWater 2016, Vienna, Austria, 11 April 2016.

27. Tiwari, M.K.; Adamowski, J. Urban water demand forecasting and uncertainty assessment using ensemble wavelet-bootstrapneural network models. Water Resour. Res. 2013, 49, 6486-6507. [CrossRef]

28. Xu, T.Y.; Qin, X.S. A Sequential Fuzzy Model with General-Shaped Parameters for Water Supply-Demand Analysis. Water Resour. Manag. 2015, 29, 1431-1446. [CrossRef]

29. Yang, S.N.; Guo, H.; Li, Y.; Liu, J.L. The Application of System Dynamics Model of City Water Demand Forecasting. Appl. Mech. Mater. 2014, 535, 440-445. [CrossRef]

30. Qi, C.; Chang, N. Bin System dynamics modeling for municipal water demand estimation in an urban region under uncertain economic impacts. J. Environ. Manage. 2011, 92, 1628-1641. [CrossRef] [PubMed]

31. Brooks, R.; Corey, A. Hydraulic Properties of Porous Media; Hydrology Paper; Colorado State University: Fort Collins, CO, USA, 1964.

32. Franchini, M.; Pacciani, M. Comparative analysis of several conceptual rainfall-runoff models. J. Hydrol. 1991, 122, 161-219. [CrossRef]

33. Tennant, D.L. Instream flow regimens for fish, wildlife, recreation and related environmental resources. Fisheries 1976, 1, 6-10. [CrossRef]

34. Kirshen, P.H.; Strzepek, K.M. Comprehensive assessment of the freshwater resources of the world. In Proceedings of the Congress of the International Association of Hydraulic Research, IAHR 1997, San Francisco, CA, USA, 10-15 August 1997; pp. $393-398$.

35. Lane, M.E.; Kirshen, P.H.; Vogel, R.M. Indicators of impacts of global climate change on US Water resources. J. Water Resour. Plann. Manag. 1999, 125, 194-204. [CrossRef]

36. Fan, L.L.; Wang, H.R.; Liu, F.L.; Lai, W.L.; Hong, S.Y. Water scarcity analysis of river basins in china based on Water Exploitation Index Plus. J. Yangtze River Sci. Res. Inst. 2017, 34, 9-14. 
37. Faergemann, H. Update on water scarcity and droughts indicator development. In EC Expert Group on Water Scarcity E Droughts; European Environment Agency: Brussels, Belgium, 2012; pp. 1-23.

38. Casadei, S.; Peppoloni, F.; Pierleoni, A. A New Approach to Calculate the Water Exploitation Index (WEI+). Water 2020, 12, 3227. [CrossRef]

39. Li, X.N.; Zhao, X.J.; Shen, X.M.; Wei, Z.X. Prediction of water demand in Gui' an city of Guizhou province in China. In Proceedings of the 2015 International Forum on Energy, Environment Science and Materials 2015, Shenzhen, China, 25-26 September 2015; pp. $1353-1358$.

40. Gong, L.L.; Huang, Q.; Dong, J.Z.; Zhao, L. Forcast of Water Requirement of Shaanxi Province in 2020. J. Arid Land Resour. Environ. 2008, 22, 169-173.

41. Huang, S. Upper Yangtze Annual Runoff Analysis and Its Forecast; Sichuan University: Chengdu, China, 2006.

42. Wang, W.P.; Chen, Y.F.; Liu, B. Regional climatic trend analysis in upper Yangtze river with Consideration of both temporal and spatial correlation. J. HoHai Univ. 2016, 45, 14-21.

43. Guan, Y.H. Extreme Climate Change and Its Trend Prediction in the Yangtze River Basin; Northwest A\&F University: Xianyang, China, 2015.

44. National Bureau of Statistics of China. China Statistical Yearbook-2011 2015; China Statistics Press: Beijing, China, 2016.

45. Changjiang Water Resources Commission of the Ministry of Water Resources. Changjiang and Southwest Rivers Water Resources Bulletin 1998-2017; Changjiang Water Resources Commission of the Ministry of Water Resources: Wuhan, China, 2018.

46. Ministry of Water Resources of China. China Water Resources Bulletin; Ministry of Water Resources of China: Beijing, China, 2015.

47. Feng, J. Simulation and Projection for Regional Climate in China by Multiple Global Climate Models; Nanjing University of Information Science \& Technology: Nanjing, China, 2012.

48. Ministry of Water Resources of China. National Comprehensive Plan for Water Resources; Ministry of Water Resources of China: Beijing, China, 2008.

49. National Development and Reform Commission of China. Outline of the 13th Five-Year Plan for the National Economic and Social Development of the People's Republic of China; National Development and Reform Commission of China: Beijing, China, 2016.

50. Center for China and World Economics, Tsinghua University. 2017-2018 China Macroeconomic Analysis and Forecast-China's Economy after the 19th CPC National Congress 20182035 2050; Center for China and World Economics, Tsinghua University: Beijing, China, 2017.

51. Ministry of Water Resources of China. The 13th Five-Year Plan for water Conservancy Development and Reform; Ministry of Water Resources of China: Beijing, China, 2016.

52. Ministry of Water Resources of China. The 13th Five-Year Plan for Building a Water-Conserving Society; Ministry of Water Resources of China: Beijing, China, 2017. 